\title{
Hand-to-mouth consumers, rule-of-thumb savers, and optimal control
}

\author{
Orlando Gomes ${ }^{1,2}$
}

Received: 14 December 2019 / Accepted: 14 June 2020

(c) Springer-Verlag GmbH Germany, part of Springer Nature 2020

\begin{abstract}
Contemporaneous research in macroeconomics is experiencing a methodological transition. The well-established representative agent optimal control model, which has served for many decades as the fundamental point of reference to approach most of the aggregate phenomena in economics, is being gradually adapted or replaced. In the new settings, agent heterogeneity prevails: while some agents eventually continue to take optimal intertemporal decisions, others do not possess the ability or the willingness to do so, and therefore resort to simple heuristics in their decision-making processes. In this study, the basic Ramsey growth model of intertemporal choice is reinterpreted in the light of the heterogeneity assumption. Four different frameworks are proposed, and the respective dynamics investigated; these frameworks contemplate: (i) the coexistence of optimal planners and hand-to-mouth consumers; (ii) the coexistence of optimal planners and rule-of-thumb savers; (iii) intertemporal discount rate heterogeneity with endogenous determination of hand-to-mouth behavior; (iv) absence of optimal planning and full heuristic behavior. The derived results point to a richness of outcomes that can only be unveiled once the simple dynamic growth setup is expanded to include different consumption-savings profiles.
\end{abstract}

Keywords Heterogeneous agents · Consumption heuristics · Intertemporal preferences $\cdot$ Hand-to-mouth consumers $\cdot$ Rule-of-thumb savers

JEL Classification O41 · E21 · D15 · C61

$凶$ Orlando Gomes omgomes@iscal.ipl.pt

1 Lisbon Accounting and Business School, Instituto Superior de Contabilidade e Administração de Lisboa (ISCAL/IPL), Av. Miguel Bombarda 20, 1069-035 Lisbon, Portugal

2 CEFAGE - ISCAL/IPL Research Center, Évora, Portugal 


\section{Introduction}

Economic agents are decision-makers. For each decision an agent takes, there is a deliberative process that involves a series of relevant dimensions: information availability, cognitive capabilities, personality traits, degree of engagement, and so forth. Typical economic analysis assumes homogeneity along the mentioned dimensions by placing individuals at an extreme position, namely the position where everyone is fully endowed with information, cognitive skills and will to arrive to the perfect decision. This is the optimal planning approach, under which agents are fully rational and the dynamics of the economy are reduced to the deliberative process of a single representative agent. ${ }^{1}$

The representative agent framework is convenient from the analytical standpoint, but it conducts to an incomplete and partial view about economic behavior. To enhance and widen economic research, one must recognize the persistence of heterogeneity: while the behavior of some, in some occasions, may approach the optimal planning prototype, there are individuals and entities that, for several reasons, do not conceive and implement optimal plans and choose, instead, to adopt simple heuristics or rulesof-thumb to govern their decision-making processes.

As the literature review in Sect. 2 will suggest, there is today a pressing need to change the way in which aggregate economic behavior is scrutinized and studied. The shift goes in the direction of attributing a prominent role to the sources and implications of agent heterogeneity. A strand of literature going in this direction is associated with the emergent research on agent-based macroeconomics. Supporters of the agent-based perspective share the belief that macroeconomics should evolve to be a science where the interaction among heterogeneous agents becomes a pervasive trivial feature (Ballot et al. 2015; Dosi et al. 2017; Gualdi et al. 2017; Guerini et al. 2018; Dawid et al. 2019; Dosi and Roventini 2019). Furthermore, agent-based economics has been the stage for a fruitful discussion about the use of simple rules-of-thumb or heuristics in deliberative processes. Haldane and Turrell $(2018,2019)$ emphasize the relevance of heuristics, however recognizing that it is a difficult task to set up a general and pervasively accepted framework of analysis to replace the strict optimality benchmark. For instance, these authors list a series of consumption functions that have been employed to replace the outcome of the typical dynamic optimal choice problem; the long extension of the list is symptomatic of how hard it is to reach a consensus on which are the rules-of-thumb economists should use to best describe the actual decisions of agents.

Beyond the contribution of agent-based modeling, although at a slower pace and with a less disruptive intent, mainstream standard macro-literature is also making its transition toward heterogeneity and the use of simple decision-making rules. Some notable macro-models, namely the new Keynesian model, have embarked on this path. In two pioneering studies, Gali et al. $(2004,2007)$ have approached the impact of consumer heterogeneity over monetary and fiscal policies. These studies have proposed

\footnotetext{
1 The notion of representative agent is pervasive in macroeconomic thought. It is the basis of the Ramsey (1928), Cass (1965), Koopmans (1965) optimal growth model; it is also the foundation underlying real business cycle theory (Kydland and Prescott 1982), as well as new Keynesian macro-models (Goodfriend and King 1997; Clarida et al. 1999; Woodford 2003).
} 
models highlighting the coexistence in the economy of two classes of agents: those who make plans and those who live hand-to-mouth. The two classes have acquired the designations of Ricardian consumers (the optimal planners, for whom the Ricardian equivalence holds) and Non-Ricardian consumers (who are the hand-to-mouth and, thus, ignore intertemporal trade-offs). The findings of this research have triggered an interesting debate concerning the determinacy of interest rate rules and the effectiveness of monetary policy (Amato and Laubach 2003; Colciago 2011; Di Bartolomeo et al. 2011), and about public finance and debt sustainability (Natvik 2012; Cho and Kim 2013; Rossi 2014; Bilbiie 2017). Kaplan et al. (2018) extended further the analysis of macroeconomic new Keynesian models under agent heterogeneity, by complementing the two-agent framework with a setting that allows for the simultaneous presence in the economy of a wide range of distinct household consumption and savings behavior; these authors called their model HANK (heterogeneous agents New Keynesian model), in opposition to the TANK (two-agent New Keynesian model) and the RANK (representative-agent New Keynesian model). ${ }^{2}$

One area of macroeconomic thought in which the implications of heterogeneity and rule-of-thumb decisions, in the terms mentioned in the above paragraphs, have not yet been consistently and systematically explored, is optimal growth theory. Therefore, the aim of the current study is to engage in a systematic evaluation of consumption-savings decisions, in the context of a typical optimal control Ramsey growth model, taking as central assumption behavioral heterogeneity. While a share of the agents eventually sticks with intertemporal planning, others follow different forms of non-optimal behavior, based in simple heuristics. Four models are explored, in which optimal planners, hand-to-mouth consumers and rule-of-thumb savers coexist. Optimal planners choose a finite degree of impatience to govern their intertemporal decisions and maximize consumption utility, hand-to-mouth consumers are the agents who adopt an infinite discount rate and, thus, only current consumption matters to them, and rule-ofthumb savers select some ad-hoc savings rate, hence behaving as in a straightforward Solow-like growth setting.

The investigation of behavioral heterogeneity in standard optimal growth models has been approached previously in the economics literature, mainly through the contribution of Krusell and Smith (1996). These authors explicitly add to the typical neoclassical growth model a cost of optimization, i.e., a cost associated with processing, computing and implementing optimal plans. In such a setting, rule-of-thumb behavior endogenously emerges for those agents who exhibit a lower capacity to face the mentioned costs. Sophisticated agents who optimize and unsophisticated agents who opt for adopting a constant savings rate will coexist in the long-run steady-state, where every agent has to weigh utility losses of not optimizing against the costs of formulating optimal plans and behaving accordingly. While the confrontation between optimal planners and rule-of-thumb decision-makers is a fundamental piece of the analysis to be pursued in this study, the study has a much broader scope, approaching many issues that the Krusell-Smith growth model overlooks: in a systematic and

\footnotetext{
2 Acharya and Dogra (2020) introduce yet another acronym: PRANK. The PRANK (pseudo-representative agent new Keynesian) model is a HANK model where one can dissociate and evaluate the separate impact of heterogeneity in the marginal propensity to consume of households and of the cyclicality of income risk.
} 
pervasive way, and relying on a same simple growth framework, this research puts into confrontation various kinds of agents and a variety of possible interactions. The protagonists are not only Ramsey-like agents and Solow-like agents who, respectively, select and adopt endogenous and exogenous savings rates, but also different kinds of hand-to-mouth agents (including, following the terminology by Kaplan et al. (2014), the wealthy hand-to-mouth). Moreover, heterogeneity becomes pervasive as one considers the possibility of coexistence of distinct rates of time preference (in the case of optimal planners) and the possibility of coexistence of distinct savings rates (for rule-of-thumb savers).

A common feature of the frameworks to be assessed is that, while agents are heterogeneous regarding their consumption-savings behavior, they are identical when it comes to their participation in the productive process. All agents contribute in the same way to production, supplying their labor force and their capital assets. They share an identical labor productivity, and therefore earn a same wage, and there is a unique capital good, that provides an identical return for anyone that holds it. Decision-making heterogeneity, though, makes agents to accumulate capital at different rates (or not to accumulate it at all) leading to long-term steady-state outcomes that differ from the benchmark case and that can only be unveiled and understood under the heterogeneity assumption. It is this variety of outcomes that one scrutinizes in the sections that follow, thus highlighting the relevance of heterogeneity and non-optimal behavior in shaping aggregate economic growth performance.

Most of the analysis throughout the paper concentrates on the evaluation of long-term outcomes, comparing steady-state consumption results of optimizers and non-optimizers. Although an analysis of transitional dynamics is, in some cases, pursued, there is no systematic evaluation and comparison of intertemporal utility across the various groups of agents. This is because the intertemporal utility outcome is, by definition, known: it should be obvious that consumption trajectories of optimal planners conduct to an utility result that outperforms the utility over time of those who do not conduct such optimal plans. However, in the context of our framework, being or not being an optimizer is not necessarily a choice, what justifies exploring the long-term performance differences between those who had the chance of establishing optimal plans and those who were forced to adopt other courses of action. Although the expected outcome might appear, at a first glance, trivial and obvious, it is not, because of the interplay between optimizers and non-optimizers, who participate in the same production process and might benefit or be penalized by how others accumulate or do not accumulate capital over time.

The remainder of the article is organized as follows. Section 2 reviews recent literature that attributes to consumption-savings heterogeneous behavior a relevant role in explaining various macroeconomic phenomena; this short survey allows to motivate and emphasize the pertinence of the current analysis. In Sects. 3 to 6, the four different models are discussed and the respective dynamics investigated; these models involve: (i) optimal planners and hand-to-mouth consumers; (ii) optimal planners and ruleof-thumb savers; (iii) heterogeneous optimal planners, with a share of hand-to-mouth consumers emerging endogenously; (iv) hand-to-mouth consumers and rule-of-thumb savers (and complete absence of optimal intertemporal planning). Section 7 concludes. 


\section{Consumption-savings heuristics in macroeconomics and growth theory}

Standard optimal growth theories (relying on both exogenous and endogenous growth models) and macro-theories of consumption and savings (such as those inspired in the life-cycle and permanent income hypotheses) are framed, according to Benartzi and Thaler (2007), by three rationality assumptions. The first is the explicit assumption that agents maximize intertemporal utility by planning the trajectories of consumption and savings that best contribute to attain the intended optimal goal. The other two assumptions are implicit and they constitute necessary conditions for the first one to hold; in order to concede that economic agents follow optimal plans, one must take for granted that: (i) they face no cognitive constraints, and (ii) they have the required willpower to fully and successfully execute the established plans. Because formal empirical evidence and casual observation do not corroborate these two assertions, it is unlikely that agents effectively behave as standard economic models suggest.

The perception that the dynamic optimization problem, in any of the many forms it might acquire, is a problem that most people in real-life circumstances cannot efficiently address, is a widely recognized fact in the context of today's economics research. In Winter et al. (2012), for instance, it is emphasized that even financially sophisticated agents are incapable of solving intertemporal problems that would allow for an optimal allocation of financial resources over time; limited computational capabilities are the main obstacle agents face when confronted with decisions involving plans about intertemporal consumption. In the same vein, Allen and Carroll (2001) emphatically claim that it would take a supercomputer and a Ph.D. degree for consumers to be able to formulate and follow the type of optimal plans that economists typically take to explain actual human behavior. Also, in Browning and Lusardi (1996) evidence is discussed on the rejection of the Euler equation as the main guide for consumption decisions, what basically signifies that households do not smooth consumption as they would if they were effectively following optimal plans.

Faced with the empirical rejection of pervasive optimal planning behavior, researchers are confronted yet with another challenge: to explain why household behavior, although not necessarily governed by optimal choices, allows to obtain outcomes that do not depart significantly from the optimality benchmark. The answer is apparently associated with the human ability to pursue trial-and-error processes that conduct to heuristics or rules-of-thumb that are sufficiently efficient to approximate optimal behavior without the need to incur in the costs associated with optimal deliberative processes (Love 2013).

Heuristics are, as defined by Gigerenzer and Brighton (2009) and Gigerenzer and Gaissmaier (2011), efficient cognitive processes that ignore potentially relevant information. The main advantage of resorting to heuristics is that they provide fast and frugal decisions, without necessarily compromising accuracy. These authors go even further, supporting the thesis that simple rules are frequently more effective and accurate than complex deliberative processes. Simple rules might not only allow to save computational resources; they may handle uncertainty more efficiently and robustly than carefully prepared plans. This less-is-more effect is an important finding that allows to justify the use and analysis of heuristics beyond the effort-accuracy trade-off. 
Therefore, it is more than reasonable to pay attention to straightforward rule-based deliberative processes of economic agents: they are not a symptom of irrational or thoughtless behavior and, hence, should not be avoided in the analysis of economic phenomena.

The two above-mentioned features, namely the unrealistically robust computational capabilities attributed to decision-makers in standard economic models and, also, the observation that actual decision-makers often resort to simple rules to choose among possible courses of action, are relevant elements to take into consideration if one desires to rethink and reassess economic growth theory in light of the actual behavior of fleshand-bone individuals who interact in realistic socioeconomic environments. Growth models, by their own nature, focus essentially on the supply-side of the economy, i.e., on the analysis of the drivers of physical capital and human capital accumulation, as well as technical progress. This is one of the reasons why growth theorists have persisted, on the demand side, in resorting invariably to the same structure of analysis, namely the one that takes a representative agent who maximizes intertemporal consumption utility. ${ }^{3}$ Adding to the growth analysis, a large array of possible departures from the optimal planning behavior will certainly add relevant insights to the exploration of growth patterns. These ideas are incorporated in the models of the following sections by assuming environments where optimal planners coexist with several types of non-optimal decision-makers, i.e., agents that replace computationally demanding optimal choice strategies by simple heuristic rules.

The most straightforward heuristic one may consider when departing from optimal planning in the context of intertemporal consumption decisions, and also the one most widely discussed in the economics literature, is also the simplest one, namely the rule that conceives consumers as hand-to-mouth, i.e., as agents that systematically consume their entire income in every time period, thus never saving or resorting to previous savings to smooth consumption. Hand-to-mouth behavior may be interpreted as irrational or as rational by a variety of reasons, the most prominent being liquidity constraints, myopia or ignorance about intertemporal opportunity costs. For instance, in Reis (2006) the existence of hand-to-mouth consumers is justified within an economic environment where information is sticky; agents who face higher costs of acquiring, absorbing and processing information (e.g., those with lower educational levels) might optimally opt to live hand-to-mouth and to never make plans. This inattentive consumers model yields results that are compatible, in the view of the mentioned author, with empirical evidence: according to Lusardi (2002), approximately one third of the US households live hand-to-mouth, consuming their current income in every time period.

The empirical work pursued by Kaplan et al. (2014) confirms that about one third of the US population is hand-to-mouth, but it also reaches another relevant finding: from this share of the population, only one-third might be classified as poor handto-mouth, i.e., as the class of agents one would expect to adopt such behavior, given their relatively tight financial conditions. The other two thirds are, in fact, what the

\footnotetext{
3 Examples of influential contributions for economic growth theory published in recent years, which make pervasive use of the benchmark intertemporal utility maximization framework, include Lucas and Moll (2014), Buera and Lucas (2018), Acemoglu and Cao (2015), Aghion et al. (2015), Akcigit et al. (2016), Benhabib et al. (2014), Grossman and Helpman (2015), and Stokey (2015).
} 
authors call wealthy hand-to-mouth. Wealthy hand-to-mouth constitute a specific class of agents, that is typically neglected in the study of economic phenomena; they are agents who hold little or no liquid wealth, but own considerable assets of an illiquid nature. Wealthy hand-to-mouth agents are a unique class of consumers, whose main distinguishing feature is that although they have the possibility to use their resources to smooth consumption over time, they choose not to do it. This is not necessarily a symptom of irrationality; it might be the rational outcome of pondering the longterm gains from investing in illiquid assets against the short-term costs emerging from having no liquid assets to smooth consumption. Both poor hand-to-mouth and rich hand-to-mouth consumers will be integrated in the growth models to approach and discuss in the following sections.

Although the above-reported estimates point to the presence of a non-negligible share of hand-to-mouth consumers in the economy, the evidence on the actual use of such a rudimentary rule-of-thumb by households in their decision-making processes is mixed. Campbell and Mankiw (1990) were the first to raise reasonable doubts on the validity of the optimal programming model, by statistically identifying a significant share of consumers that apparently do not plan for the future. This is a result that has been subject to strong controversy, with arguments being presented in both directions, i.e., in favor and against. Weber (2002) and Havranek and Sokolova (2020), among many others, do not find evidence of relevant deviations from consumption smoothing, what indicates that probably the number of consumers who follow rules-of-thumb when defining the respective consumption paths is not significant. In the opposite direction, Lusardi (1996), Lettau and Uhlig (1999) and Kiley (2010), corroborate the Campbell-Mankiw result and give emphasis to hand-to-mouth behavior.

More sophisticated patterns of eventual departure from optimal planning might be associated to the wide range of psychological factors influencing the savings behavior of individuals, factors that in no way can be associated with a plain optimal programming model. Gerhard et al. (2018) investigate a large number of drivers of savings behavior, including financial literacy, the most relevant personality traits, self-control, optimism, attitudes toward savings, and regulatory focus. All these drivers contribute to shape decision rules that involve motivations that go beyond economic criteria. Additionally, fully understanding consumption-savings household choices and integrating them in a comprehensive growth analysis might require a deep look at the inner structure of households; recent literature has emphasized the relevance of family economics (Doepke and Tertilt 2016), arguing that building macro-models under the representative agent assumption necessarily hides a wide and rich set of possible conflict relations and interactions within families that constitute an important element to understand decisions with an impact at the macro-level.

The adaptation of the representative growth model to include a wide variety of household behaviors and the evaluation of the corresponding implications, which is the proposed contribution of this study, might be interpreted as a form of establishing a bridge between the orthodox neoclassical paradigm and the complexity approach that is being increasingly adopted to model economic behavior. De Grauwe (2010) lays down a clear distinction between two types of economic models: the conventional ones, in which agents fully understand the environment in which they act and therefore are capable of formulating and implementing optimal plans, and those in which agents 
face cognitive and informational constraints and make use of simple rules to guide their behavior. While these may appear to be two completely different views of the world (top-down vs bottom-up models), the distinction does not have to be so dramatic; there are points of contact that emerge once heterogeneity, interaction and the employment of heuristics are associated to conventional macroeconomic models.

\section{Optimizers versus hand-to-mouth consumers}

Conceive, as a first setting, an economy populated by a large number of individual agents, who amount to a total value of $L$; each agent is endowed with one unit of labor that is used in the production of a homogeneous good. The agents are of two types; part of the population, $L^{O}$, is composed by optimal planners who select a same finite rate $\rho \geq 0$ to discount future utility. The remainder, $L^{H}$, are hand-to-mouth consumers, i.e., agents who set the discount rate to infinity (only current consumption matters, and all future utility is disregarded). In this setting, the total amount of labor and the labor shares are assumed to be constant over time; the share of hand-to-mouth consumers will be represented by $\lambda \equiv \frac{L^{H}}{L}$.

Hand-to-mouth agents do not save, and therefore do not contribute to the accumulation of capital. At each time period, $t$, the total stock of physical capital, $K(t) \geq 0$, is concentrated in the hands of the agents who conduct optimal plans. Concerning the production technology, a typical neoclassical production function is taken, $Y(t)=F[K(t), L]$, with $Y(t) \geq 0$ representing aggregate income. The production function exhibits diminishing marginal returns to both inputs and constant returns to scale; furthermore, it displays constant output-capital and output-labor elasticities,

$$
F_{K} \frac{K(t)}{F(.)}=\alpha ; \quad F_{L} \frac{L}{F(.)}=1-\alpha ; \alpha \in(0,1)
$$

The production function is presentable in per capita terms, after defining $k^{O}(t) \equiv \frac{K(t)}{L^{O}}$ and $y(t) \equiv \frac{Y(t)}{L}$,

$$
y(t)=f\left[(1-\lambda) k^{O}(t)\right]
$$

Agents in the economy are endowed with identical productivity levels, and therefore receive an identical competitive wage, which is

$$
w(t)=f_{L}=(1-\alpha) f\left[(1-\lambda) k^{O}(t)\right]
$$

As stated above, the hand-to-mouth consumers do not hold capital and, therefore, their individual consumption level, at every date $t$, coincides with the wage in (3): $c^{H}(t)=w(t)$. Optimal planners earn, besides labor income, returns from capital at gross rate

$$
r(t)=f_{K}=\alpha \frac{f\left[(1-\lambda) k^{O}(t)\right]}{(1-\lambda) k^{O}(t)}
$$


The distinguishing feature between the two profiles of agents is that for the optimal planners one needs to solve the corresponding optimal control problem in order to derive the consumption time path. An optimal planner maximizes a standard objective function,

$$
V(t)=\int_{0}^{\infty} u\left[c^{O}(t)\right] \exp (-\rho t) \mathrm{d} t
$$

In Eq. (5), $u\left[c^{O}(t)\right]$ is a constant rate of risk aversion (CRRA) utility function and $c^{O}(t)$ stands for the consumption of an optimizing agent. This agent faces the following resource constraint,

$$
\dot{k}^{O}(t)=[r(t)-\delta] k^{O}(t)+w(t)-c^{O}(t), k^{O}(0)=k_{0}^{O} \text { given }
$$

In Eq. (6), $\delta \in(0,1)$ represents the capital depreciation rate. Taking the wage rate in expression (3) and the return rate in expression (4), constraint (6) is rewritten under the form

$$
\dot{k}^{O}(t)=\left(1+\alpha \frac{\lambda}{1-\lambda}\right) f\left[(1-\lambda) k^{O}(t)\right]-c^{O}(t)-\delta k^{O}(t), k^{O}(0)=k_{0}^{O} \text { given }
$$

Let parameter $\theta \in(0, \infty) \backslash\{1\}$ represent the inverse of the elasticity of intertemporal substitution between consumption at consecutive time periods. Trivial computation of optimality conditions leads to the following equation for the growth of consumption of an individual optimal planner,

$$
c^{O}(t)=\frac{1}{\theta}\left\{\alpha\left(1+\alpha \frac{\lambda}{1-\lambda}\right) \frac{f\left[(1-\lambda) k^{O}(t)\right]}{k^{O}(t)}-(\rho+\delta)\right\} c^{O}(t)
$$

In possession of Eqs. (7) and (8), one can address both steady-state properties and transitional dynamics.

Let us start by briefly approaching the balanced growth path properties. Applying steady-state condition $c^{O}(t)=0$ to Eq. (8), the following equality is derived,

$$
f\left[(1-\lambda)\left(k^{O}\right)^{*}\right]=\frac{\rho+\delta}{\alpha\left(1+\alpha \frac{\lambda}{1-\lambda}\right)}\left(k^{O}\right)^{*}
$$

Given that the 1.h.s. of (9) is an increasing concave function and that the r.h.s. is an increasing straight line, there is a unique non-zero solution for the above equation, which corresponds to a positive capital stock. The steady-state level of consumption is directly determinable by applying condition $\dot{k}^{O}(t)=0$ to Eq. (7), 


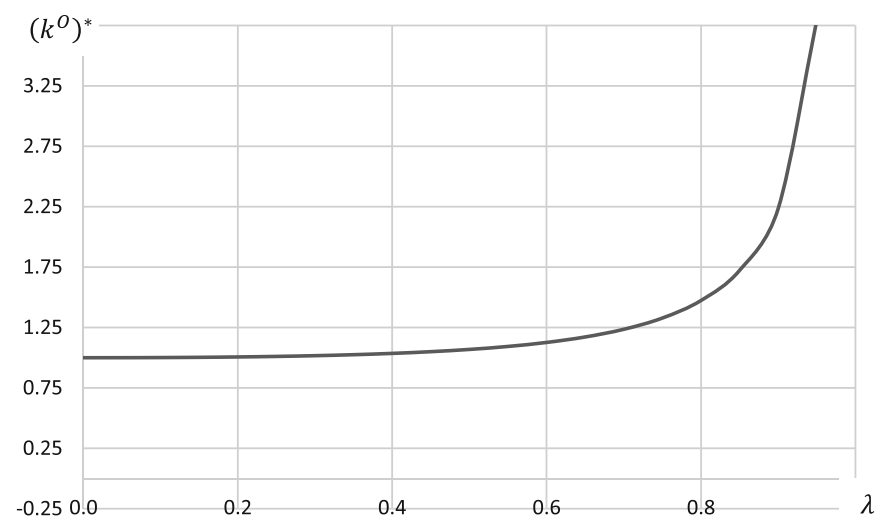

Fig. 1 Steady-state per capita capital stock, for different values of $\lambda$

$$
\left(c^{O}\right)^{*}=\left(\frac{1}{\alpha} \rho+\frac{1-\alpha}{\alpha} \delta\right)\left(k^{O}\right)^{*}
$$

The above reasoning allows to state that, in the optimal planners vs hand-to-mouth consumers model, there is a unique non-trivial steady-state point $\left[\left(k^{O}\right)^{*},\left(c^{O}\right)^{*}\right]$, which defines the long-run state in which an optimal planner will locate.

The long-run state given by Eqs. (9), (10) is a general result that encloses the typical Ramsey model balanced growth path as a particular case, for $\lambda=0$ (no hand-to-mouth consumers). Observe that, in Eq. (9), as $\lambda$ increases, the term in the 1.h.s. of the expression also increases; the term in the r.h.s. falls. Since the equilibrium steady-state point is found in the intersection of these two curves, an increase in the share of rule-of-thumb consumers will necessarily imply a higher steady-state level for $\left(k^{O}\right)^{*}$. Such outcome signifies that the presence in the economy of hand-to-mouth consumers penalizes optimal planners; these will need to save more (hence, consume less), in the steady-state, in order to fulfill their utility maximization goal. Figure 1 illustrates this result, by considering a specific array of parameter values $(\rho=0.02 ; \delta=0.025 ; \alpha=0.25)$ and a Cobb-Douglas production technology with the technological index normalized to 1 .

If one multiplies the steady-state per capita stock of capital by the share of individuals that accumulate capital, $K^{*}=\left(k^{O}\right)^{*}(1-\lambda) L$, one observes that as additional hand-to-mouth consumers are introduced to replace for optimal planners, the aggregate stock of capital falls (Fig. 2). A growing population of hand-to-mouth consumers provokes a fall in aggregate savings that translates in a lower steady-state capital stock. Hence, with the rise of the share of hand-to-mouth households, individual optimal planners are required to save more, although this increase in individual savings is, in any case, insufficient to cover the loss in aggregate savings that takes place in the balanced growth path.

Recover consumption levels, as presented above, to state the following result, 


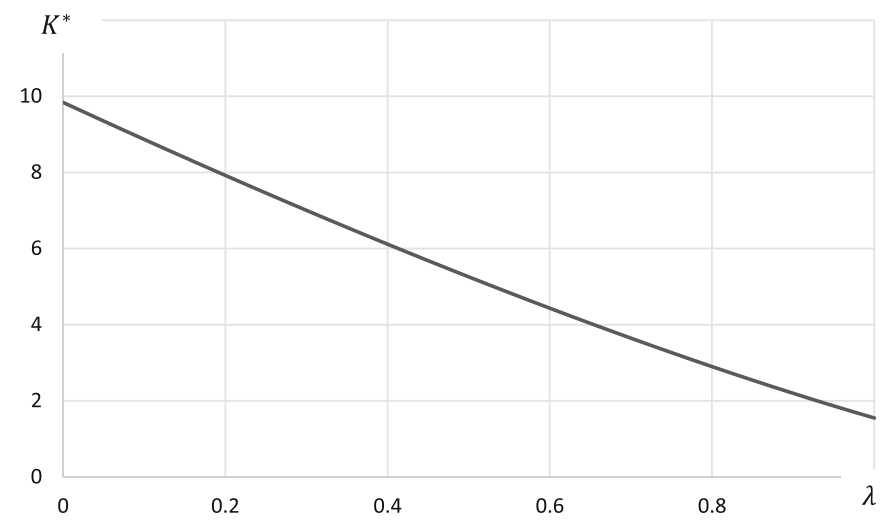

Fig. 2 Steady-state aggregate capital stock, for different values of $\lambda$

Proposition 1 In the optimal planners vs hand-to-mouth consumers model, the steady-state consumption level of an optimal planner is larger than the steady-state consumption of a hand-to-mouth consumer, regardless of the value of the share of hand-to-mouth consumers in the economy.

\section{Proof See "Appendix”.}

There is a straightforward economic rationale underlying the above outcome. Recall that the assumed economy is framed by a competitive environment, in which households supply labor inelastically and where all labor units are equally productive. In this setting, wages are identical across agents, but only some of them, the optimal planners are endowed with the ability to save. Savings will allow for sustained capital earnings over time and, thus, for additional income in the steady-state, which will serve the purpose of increasing consumption beyond labor income.

The result in Proposition 1 is graphically illustrated in Fig. 3. The two curves in the graphic represent the levels of consumption of an optimizer and of a hand-to-mouth consumer. The two lines never intersect, and the one respecting to the consumption of an optimal planner remains in any case above the line drawn to represent the level of consumption of a hand-to-mouth household (the parameter values used for the graphical representation are the same as for the previous figures). Optimal behavior allows not only for deriving the best possible trajectory for consumption over time; it also implies that optimizers will attain a higher steady-state consumption level than hand-to-mouth consumers, thus reaching higher utility levels in the balanced growth path.

Concerning local transitional dynamics, the optimal planners vs hand-to-mouth consumers model replicates the same qualitative result as in the typical Ramsey model $(\lambda=0)$. The underlying linearized system is saddle-path stable. To confirm this outcome, proceed with the linearization of the optimal planner dynamic system, (7)(8), in the steady-state vicinity, which yields 


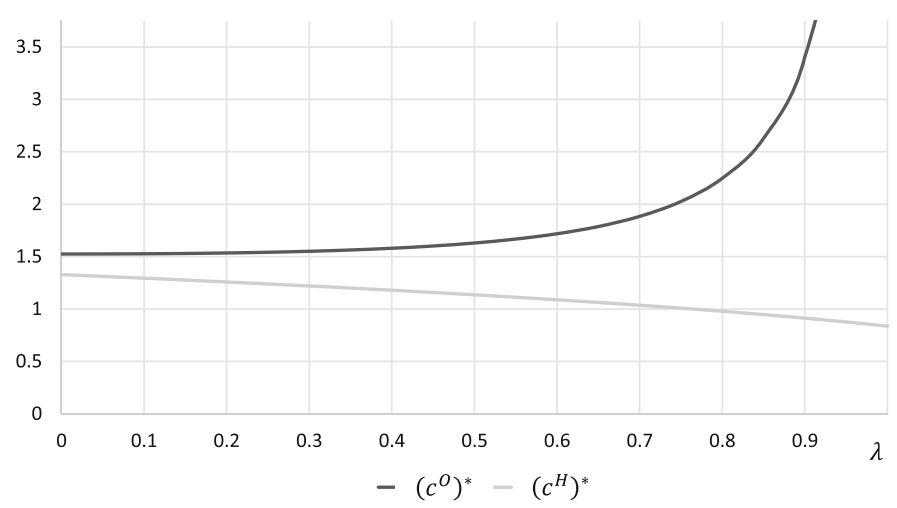

Fig. 3 Per capita steady-state consumption, for different values of $\lambda$

$$
\left[\begin{array}{c}
k^{O}(t) \\
\dot{c}^{O}(t)
\end{array}\right]=\left[\begin{array}{cc}
\rho & -1 \\
-\frac{1-\alpha}{\theta}(\rho+\delta)\left(\frac{1}{\alpha} \rho+\frac{1-\alpha}{\alpha} \delta\right) & 0
\end{array}\right]\left[\begin{array}{c}
k^{O}(t)-\left(k^{O}\right)^{*} \\
c^{O}(t)-\left(c^{O}\right)^{*}
\end{array}\right]
$$

System (11) is the same one would have obtained if only optimizers populated the economy (parameter $\lambda$ is irrelevant in this context). The equilibrium underlying the behavior of optimal planners will be a saddle-path equilibrium with the stable arm given by expression

$$
c^{O}(t)-\left(c^{O}\right)^{*}=\left(\frac{\rho}{2}+\sqrt{\left(\frac{\rho}{2}\right)^{2}+\frac{1-\alpha}{\theta}(\rho+\delta)\left(\frac{1}{\alpha} \rho+\frac{1-\alpha}{\alpha} \delta\right)}\right)\left[k^{O}(t)-\left(k^{O}\right)^{*}\right]
$$

Because parameter $\lambda$ does not affect the adjustment to the steady-state locus of the optimizing agents, they will follow the same stable trajectory, given their initial stock of physical capital, regardless of the percentage of hand-to-mouth consumers in the economy.

\section{Optimization costs}

The condition presented along with Proposition $1,\left(c^{O}\right)^{*}>\left(c^{H}\right)^{*}, \forall \lambda \in(0,1)$, delivers the expected result pointing to the sub-optimal performance of the hand-tomouth rule. Departing from optimal planning is not an option agents willingly follow, if they have the opportunity and the possibility to maximize intertemporal consumption utility. However, this outcome might change, as suggested by Krusell and Smith (1996), if one associates to the optimizers' problem the inability to collect and process all the relevant information, some sort of inattention, or any other impediment of a cognitive nature that somehow constrains the ability to decide optimally (DellaVigna 2009; Gabaix 2014). In what follows, the implications of associating imperfect optimization to the problem of the optimal planner are investigated. 
The mentioned cognitive / inattention costs are translated into a processing effort that implies spending $(1+\tau) c^{O}(t)$ in order to consume $c^{O}(t)$, with $\tau>0$ (in line with iceberg costs in international trade theory). The modified capital accumulation constraint comes

$$
\begin{aligned}
& k^{O}(t)=\left(1+\alpha \frac{\lambda}{1-\lambda}\right) f\left[(1-\lambda) k^{O}(t)\right]-(1+\tau) c^{O}(t) \\
& -\delta k^{O}(t), k^{O}(0)=k_{0}^{O} \text { given }
\end{aligned}
$$

The equation of motion for consumption remains identical to (8). Therefore, the steadystate capital level is the same, while the consumption long-run equilibrium value is now

$$
\left(c^{O}\right)^{*}=\frac{1}{1+\tau}\left(\frac{1}{\alpha} \rho+\frac{1-\alpha}{\alpha} \delta\right)\left(k^{O}\right)^{*}
$$

Comparing the new value of $\left(c^{O}\right)^{*}$ with $\left(c^{H}\right)^{*}$, as displayed in the proof of Proposition 1 , a new result is derived.

Proposition 2 In the optimal planners versus hand-to-mouth consumers model, when inattention, informational or cognitive costs are associated to optimal planning, the steady-state consumption level of an optimal planner is higher than the steady-state consumption of a hand-to-mouth consumer if, and only if, the inattention costs are sufficiently low to satisfy condition

$$
\tau<\frac{\alpha}{(1-\alpha)(1-\lambda)}\left\{1-[1-(1-\alpha) \lambda] \frac{\delta}{\rho+\delta}\right\}
$$

Proof See "Appendix".

For relatively low costs associated with establishing optimal plans, planners have higher steady-state consumption levels than hand-to-mouth consumers. This result is reverted when $\tau$ is higher than the computed threshold in the r.h.s. of (15). Figure 4 displays this threshold for the same parameter values used in previous illustrations. Note that for a relatively low share of hand-to-mouth consumers, the condition required to break inequality $\left(c^{O}\right)^{*}>\left(c^{H}\right)^{*}$ is not too demanding; however, as $\lambda$ increases, the value of $\tau$ that is necessary to make the consumption of hand-to-mouth agents a higher value than the consumption of optimal planners becomes progressively larger.

Figure 5 presents a new version of Fig. 3, for $\tau=0.3$. In the figure, it is visible that for a relatively low percentage of hand-to-mouth consumers (lower than around $\lambda=0.35)$ it compensates, under a steady-state perspective, to be a hand-to-mouth agent rather than an optimizer. A free-riding issue arises in the present context. As the graphical representation unveils, the individual agent might benefit from being a hand-to-mouth consumer if there is a relatively large number of agents willing to bear the costs of optimization. As the share of hand-to-mouth consumers increases, it is no longer beneficial to be a non-optimizing agent. 


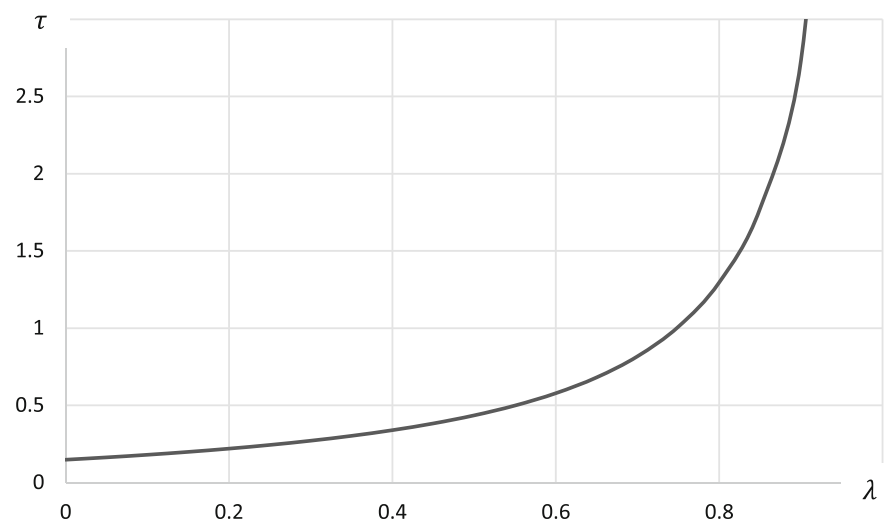

Fig. 4 Relation between $\tau$ and $\lambda$, in the optimization costs scenario

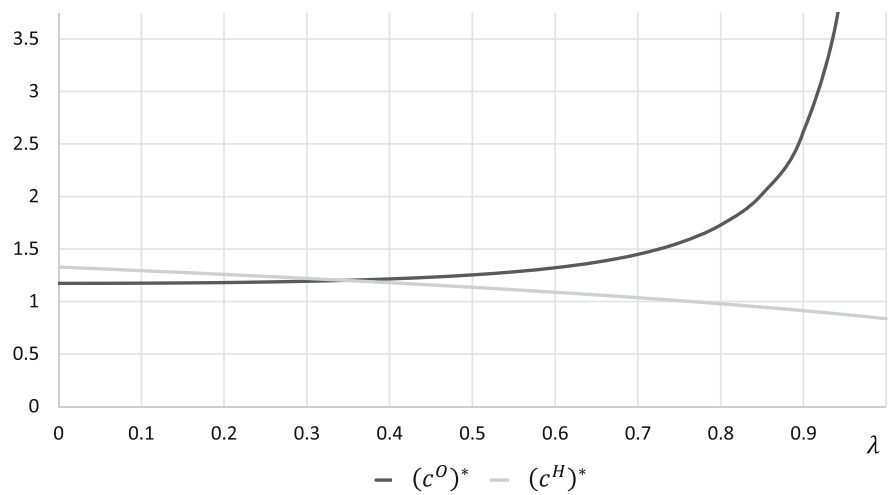

Fig. 5 Per capita steady-state consumption for different values of $\lambda$, in the presence of optimization costs

For a given value of the optimization cost parameter, $\tau$, if one sets aside any constraint agents might face concerning the migration from one behavioral type to the other, one should expect the value of share $\lambda$ to move and, namely to converge, through an arbitrage mechanism, to the value for which $\left(c^{O}\right)^{*}=\left(c^{H}\right)^{*}$. This is the equilibrium locus such that incentives to change status vanish. Otherwise, if households do not possess the faculty of changing behavior, their relative outcome will be dependent upon how many individuals are associated with one or the other decision rule (optimal or non-optimal).

\section{The wealthy hand-to-mouth}

A different perspective on hand-to-mouth consumers is the one suggested by Kaplan et al. (2014), who characterize a specific class of agents, namely those who hold sizable amounts of illiquid assets, although they own no or little liquid wealth. As remarked in Sect. 2, empirical evidence supports the notion that these agents are the large majority 
of hand-to-mouth consumers. Consumers with this behavior are designated by wealthy hand-to-mouth.

In the context of the examined model, define wealthy hand-to-mouth consumers as the consumers that own capital, thus receiving capital returns that they will reinvest in production; their consumption will be circumscribed, in every period, to the respective wage income. The formal presentation of a model where optimal planners and wealthy hand-to-mouth coexist is not substantively different from the one previously presented. Let $L=L^{O}+L^{W}$ be the total amount of labor where, as before, $L^{O}$ stands for the quantity of labor held by optimal planners; $L^{W}$ is the labor endowment of the wealthy hand-to-mouth. Consider, as well, that the capital stock is allocated to the two types of agents, i.e., $K(t)=K^{O}(t)+K^{W}(t)$. The resource constraint of a hand-to-mouth consumer can be written in the following terms:

$$
k^{W}(t)=\left\{[r(t)-\delta] k^{W}(t)+w(t)\right\}-w(t)=[r(t)-\delta] k^{W}(t), k^{W}(0)=k_{0}^{W} \text { given }
$$

In Eq. (16), the term $[r(t)-\delta] k^{W}(t)+w(t)$ represents the overall income of the agent; because she consumes her wage, the saved income is the net return on capital. Variable $k^{W}(t) \equiv \frac{K^{W}(t)}{L^{W}}$ is the per capita capital stock of the wealthy hand-to-mouth. Let $\tilde{\lambda} \equiv \frac{L^{W}}{L}$; Eq. (16) is equivalent to:

$$
\begin{aligned}
& k^{W}(t)=\alpha \frac{k^{W}(t)}{k(t)} f[k(t)]-\delta k^{W}(t), k(t) \\
& =\tilde{\lambda} k^{W}(t)+(1-\tilde{\lambda}) k^{O}(t), k^{W}(0)=k_{0}^{W} \text { given }
\end{aligned}
$$

The consumption of a wealthy hand-to-mouth household is $c^{W}(t)=(1-\alpha) f[k(t)]$. Optimizers maximize objective function $V(t)$, as displayed in (5). The maximization of $V(t)$ is subject to a constraint similar to (6), which, in the current case, is equivalent to

$$
\dot{k^{O}}(t)=\left[(1-\alpha)+\alpha \frac{k^{O}(t)}{k(t)}\right] f[k(t)]-c^{O}(t)-\delta k^{O}(t), k^{O}(0)=k_{0}^{O} \text { given }
$$

Solving the optimality problem, the following differential equation for consumption is computed,

$$
c^{O}(t)=\frac{1}{\theta}\left\{\alpha\left[1+(1-\alpha)(1-\tilde{\lambda})\left(1-\frac{k^{O}(t)}{k(t)}\right)\right] \frac{f[k(t)]}{k(t)}-(\rho+\delta)\right\} c^{O}(t)
$$

The above displayed differential equations allow for a straightforward characterization of the steady-state. Applying condition $\dot{k}^{\dot{W}}(t)=0$ to Eq. (17), one determines the steady-state average stock of capital, per unit of labor, 


$$
\alpha f\left(k^{*}\right)=\delta k^{*}
$$

Under Eq. (20), there is a unique non-trivial steady-state value $k^{*}$, since the 1.h.s. of the equation is an increasing concave function and the r.h.s. is a positively sloped straight line. From Eq. (19), one draws the steady-state endowment of capital of an optimal planner, which is, as the expression reveals, lower that the average capital stock,

$$
\left(k^{O}\right)^{*}=\left[1-\frac{1}{(1-\alpha)(1-\tilde{\lambda})} \frac{\rho}{\delta}\right] k^{*}
$$

Condition $1-\tilde{\lambda}>\frac{1}{1-\alpha} \frac{\rho}{\delta}$ must be satisfied, in order to guarantee that $\left(k^{O}\right)^{*}>0$ and, hence, that optimizers subsist in a model where the participation in production is shared with wealthy hand-to-mouth agents. The condition sets an upper bound on the value of the share of wealthy hand-to-mouth workers. Notice that the presence of wealthy hand-to-mouth consumers will trigger an over-accumulation of capital relatively to the benchmark full optimization scenario. In this case, the rate of return on capital will fall relatively to such scenario, pushing optimal planners to an inefficient dissaving outcome.

The assets accumulated in the steady-state by a wealthy hand-to-mouth individual amount to, given the definition of $k(t)$,

$$
\left(k^{W}\right)^{*}=\left(1+\frac{1}{1-\alpha} \frac{1}{\widetilde{\lambda}} \frac{\rho}{\delta}\right) k^{*}
$$

Observe that $\left(k^{O}\right)^{*}<\left(k^{W}\right)^{*}, \forall \tilde{\lambda} \in(0,1)$. Wealthy hand-to-mouth consumers have access to a larger endowment of capital in the steady-state than optimizers.

Steady-state consumption of an optimal planner is, for $\dot{k}^{\dot{O}}(t)=0$ applied to differential equation (18),

$$
\left(c^{O}\right)^{*}=\frac{1-\alpha}{\alpha} \delta k^{*}
$$

The steady-state consumption level of a wealthy hand-to-mouth follows directly from the respective definition,

$$
\left(c^{W}\right)^{*}=(1-\alpha) f\left(k^{*}\right)
$$

Because $k^{*}>0$ exists and is unique, and capital endowments and consumption levels of both types of agents depend linearly on $k^{*}$, unique steady-state values are also found for each of the relevant variables.

The main difference between the outcome in the optimal planners versus wealthy hand-to-mouth consumers model and the outcome previously attained for the nonwealthy hand-to-mouth households framework is that now there is a threshold on the share of wealthy hand-to-mouth agents that must be satisfied in order for the model 
to have a feasible solution. In particular, $\tilde{\lambda}$ must be lower than a specific combination of parameter values, $\widetilde{\lambda}<1-\frac{1}{1-\alpha} \frac{\rho}{\delta}$. Furthermore, given the consumption values computed above, it is straightforward to arrive to the following fundamental result,

Proposition 3 In the optimal planners versus wealthy hand-to-mouth consumers model, the steady-state consumption levels will be identical across agent types, i.e., $\left(c^{W}\right)^{*}=\left(c^{O}\right)^{*}$.

Proof Simply note that under condition (20), the r.h.s. of expressions (23) and (24) are the same value.

The result in Proposition 3 contrasts with the one previously derived in the poor hand-to-mouth setting. While in that setting hand-to-mouth consumers accomplished lower levels of steady-state consumption than optimal planners, now this does not happen: every agent will consume the same. This occurs because in the steady-state, following Eq. (20), the equilibrium interest rate equals the capital depreciation rate. Consequently, capital accumulation just serves the purpose of replacing depreciated capital, meaning that, for both categories of agents, consumption will correspond to labor income (which, in turn, is identical across agents, given the equal productivity assumption).

Concerning transitional dynamics, in the current setup one has to consider, relatively to the previous setting, an additional dimension, i.e., one cannot simply address the capital-consumption dynamics of optimal planners without regarding also the process of accumulation of capital of the hand-to-mouth consumers, since they are intertwined. In the optimal planners versus wealthy hand-to-mouth consumers model, transitional dynamics involve three dimensions, two of them stable (attached to the capital variables of each category of agents) and the other one unstable (associated with the endogenous control variable, the consumption level of a representative optimal planner). As in trivial Ramsey growth models, transitional dynamics are characterized by saddle-path stability.

The above assertion is straightforward to verify by taking differential equations (17), (18), and (19) and linearizing them in the vicinity of the steady-state. This procedure leads to the following matricial system,

$$
\left[\begin{array}{c}
k^{W}(t) \\
k^{O}(t) \\
c^{O}(t)
\end{array}\right]=\left[\begin{array}{ccc}
j_{11} & j_{12} & 0 \\
\frac{\widetilde{\lambda}}{1-\lambda} \rho & \rho & -1 \\
j_{31} & j_{32} & 0
\end{array}\right]\left[\begin{array}{c}
k^{W}(t)-\left(k^{W}\right)^{*} \\
k^{O}(t)-\left(k^{O}\right)^{*} \\
c^{O}(t)-\left(c^{O}\right)^{*}
\end{array}\right]
$$

with

$$
\begin{array}{r}
j_{11}=\frac{\tilde{\lambda}}{1-\widetilde{\lambda}} j_{12}=-[\rho+(1-\alpha) \tilde{\lambda} \delta] \\
j_{31}=-\frac{1}{\theta} \frac{1-\alpha}{\alpha} \tilde{\lambda} \delta[\rho+(1-\alpha)(\rho+\tilde{\lambda} \delta) ;] \\
j_{32}=-\frac{1}{\theta} \frac{1-\alpha}{\alpha}(1-\tilde{\lambda}) \delta\{\rho+(1-\alpha)[\rho+(1+\tilde{\lambda}) \delta]\}
\end{array}
$$


Trace and determinant of the Jacobian matrix in system (25) are, respectively, $\operatorname{Tr}(J)=$ $-(1-\alpha) \tilde{\lambda} \delta<0$ and $\operatorname{Det}(J)=\frac{1}{\theta} \frac{(1-\alpha)^{2}}{\alpha}(1-\tilde{\lambda}) \delta^{2}[\rho+(1-\alpha) \tilde{\lambda} \delta]>0$. From the negative trace, one infers that it exists at least one negative eigenvalue associated with the Jacobian matrix; the positive determinant implies that the number of negative eigenvalues can only be zero or two. Combining both conditions, one identifies the existence of two negative eigenvalues, meaning that the three-dimensional system has two stable dimensions, i.e., there is saddle-path stability. The number of stable dimensions has correspondence with the number of state variables (the capital stock of each type of agent); the unstable dimension exists, as in the original Ramsey model, associated with the control variable, which in this case is the consumption of an agent engaged in optimal planning.

Next, recover optimization costs, as previously applied to the intertemporal choices of optimal planners and expressed through parameter $\tau>0$. The inclusion of such costs in the current version of the model will modify the previously accomplished steady-state outcome. Although the consumption of wealthy hand-to-mouth agents remains identical, and the same occurs with respect to the capital stock of each type of agent, there is a fundamental modification: inattention or informational costs faced by optimizers will lower the balanced growth path level of consumption of this class of agents. If, in the absence of costs associated with the optimization process, the steadystate consumption levels of optimizers and non-optimizers were identical, now, with the optimal planners facing a cost associated with their deliberative process, they will be able to consume less than individuals that do not plan for the future. In this case, the steady-state consumption level of an optimal planner is,

$$
\left(c^{O}\right)^{*}=\frac{1}{1+\tau} \frac{1-\alpha}{\alpha} \delta k^{*}
$$

Because $\left(c^{W}\right)^{*}=\left(c^{O}\right)^{*}$ in the absence of optimization costs, expression (26) directly implies that $\left(c^{O}\right)^{*}<\left(c^{W}\right)^{*}$, i.e., the steady-state consumption level of the wealthy hand-to-mouth is larger than the consumption of optimal planners.

In the current scenario, if the possibility of transition between household types existed, in the long-term all agents would prefer to be wealthy hand-to-mouth consumers, because they would access a higher level of consumption, and thus, a higher utility level. However, two caveats should be kept in mind: first, the mobility across states might not be possible or cognitively feasible (an agent that has chosen to be hand-to-mouth probably could not meet the required standards to act as an optimizer) and, second, recall that this is a steady-state outcome; there is no reason to believe on the supremacy of consumption of hand-to-mouth consumers over the transitional phase.

\section{Optimizers versus rule-of-thumb savers}

Alternatively to the economy populated by optimizers versus hand-to-mouth agents, consider now a setting where the non-optimizing agents choose to consume a constant 
positive share of their overall income (asset returns plus wages). Proceeding as in the previous section, regarding the determination of capital flows, the following capital accumulation constraint for a rule-of-thumb saver is derived,

$$
\dot{k^{S}}(t)=s\left[(1-\alpha)+\alpha \frac{k^{S}(t)}{k(t)}\right] f[k(t)]-\delta k^{S}(t), k^{S}(0)=k_{0}^{S} \text { given }
$$

with $s \in(0,1)$ a constant savings rate. Variable $k^{S}(t)$ represents the per capita asset endowment of a rule-of-thumb saver, and the average per capita capital stock is $k(t)=$ $\widehat{\lambda} k^{S}(t)+(1-\widehat{\lambda}) k^{O}(t)$; in this expression, $k^{O}(t)$ is defined as previously (capital stock of an optimizer), and $\widehat{\lambda}$ represents the share of agents that are rule-of-thumb savers. The resource constraint of an optimal planner takes exactly the form already presented in Eq. (18). The differential equation for the consumption of the optimal planners is similar to the one displayed in Eq. (19), and the consumption of rule-of-thumb savers is:

$$
c^{S}(t)=(1-s)\left[(1-\alpha)+\alpha \frac{k^{S}(t)}{k(t)}\right] f[k(t)]
$$

The above information allows for a straightforward characterization of the steadystate. Take Eqs. (27) and (19); evaluating these for $k^{S}(t)=0$ and $c^{o}(t)=0$, the following steady-state ratio is derived,

$$
\frac{\left(k^{O}\right)^{*}}{\left(k^{S}\right)^{*}}=\frac{1+\frac{1}{1-\lambda} \Psi}{1-\frac{1}{\lambda} \Psi}
$$

with $\Psi \equiv \frac{\frac{\rho+\delta}{\delta} \frac{s}{\alpha}-1}{\frac{\rho+\delta}{\delta} \frac{s}{\lambda}-(1-\alpha)}$. Capital ratio (29) is a feasible equilibrium result only if the expression in the r.h.s. of (29) is a positive value. Such outcome requires condition $-(1-\widehat{\lambda})<\Psi<\widehat{\lambda}$ to be satisfied; this condition, in turn, is equivalent to the following double inequality on the savings rate,

$$
\frac{\alpha \delta}{\rho+\delta} \widehat{\lambda}\left[\frac{2}{\widehat{\lambda}+\alpha(1-\widehat{\lambda})}-1\right]<s<\frac{\alpha \delta}{\rho+\delta}\left(\frac{1}{1-\alpha}-\widehat{\lambda}\right)
$$

Double inequality (30) demands yet another constraint to hold, namely $\widehat{\lambda}<\frac{\alpha}{1-\alpha}$; otherwise, there is no positive savings allowing for the coexistence of the two types of agents in the long-term equilibrium scenario.

The above constraints impose relevant boundaries on the possible interaction between optimal planners and rule-of-thumb savers. First, there is an upper bound on the share of rule-of-thumb savers that can coexist with optimizers; this upper bound is directly determined by the output-capital elasticity: a high-output capital elasticity makes it feasible to relax such boundary (if $\alpha \geq 1 / 2$, then the boundary simply ceases to exist). Second, condition (30) assigns upper and lower bounds to the savings rate. Observe that one cannot, in this case, determine specific capital stocks for each type 
of agent in the steady-state; every ratio $\frac{\left(k^{O}\right)^{*}}{\left(k^{S}\right)^{*}}$ obeying (29) is an admissible steadystate solution, as long as the boundaries on $s$ are respected. Within such bounds, as the savings rate increases, ratio $\frac{\left(k^{O}\right)^{*}}{\left(k^{S}\right)^{*}}$ also increases; specifically, the following set of relations is derived,

- If $s<\frac{\alpha \delta}{\rho+\delta}$, then $\Psi<0$ and $\left(k^{O}\right)^{*}<\left(k^{S}\right)^{*}$;

- If $s=\frac{\alpha \delta}{\rho+\delta}$, then $\Psi=0$ and $\left(k^{O}\right)^{*}=\left(k^{S}\right)^{*}$;

- If $s>\frac{\alpha \delta}{\rho+\delta}$, then $\Psi>0$ and $\left(k^{O}\right)^{*}>\left(k^{S}\right)^{*}$.

A relatively high savings rate for the rule-of-thumb savers delivers a steady-state result where the assets held by an optimal planner are a larger value than the assets in the hands of a rule-of-thumb saver, and vice-versa. Although this result might appear counterintuitive, it is the outcome that actually emerges from the interplay between optimal planners and households choosing an exogenous savings rate. The coexistence of optimizers and exogenous savers is possible only for a relatively small window of possible savings rates. Outside such window, the players will not benefit in any way in maintaining their cooperation and they will follow separate paths concerning the participation in production.

Observe, in particular, that $s=\frac{\alpha \delta}{\rho+\delta}$ corresponds to the case in which capital stocks are identical in the balanced growth path; this is the case in which the savings rate selected by exogenous savers is the one that optimal agents will accomplish in the long-run. As $s$ departs from this value (decreasing or increasing), it raises the chance of breaking down the compatibility between the two classes of agents. Consequently, mutually beneficial coexistence requires rule-of-thumb savers to select a savings rate that does not depart significantly from the long-term savings rate that is generated through optimal planning.

Under $k^{S}(t)=0$, and given steady-state result (29), the following relation is derived, which holds for any $s$ obeying (30),

$$
s\left(1-\frac{\alpha}{\widehat{\lambda}} \Psi\right) f\left(k^{*}\right)=\delta\left(1-\frac{1}{\widehat{\lambda}} \Psi\right) k^{*}
$$

As in previous occasions, an increasing and concave 1.h.s. and an increasing and linear r.h.s. guarantee the uniqueness of $k^{*}>0$. Notice that the unique value of $k^{*}$ is obtainable for any possible combination of $\left(k^{O}\right)^{*}$ and $\left(k^{S}\right)^{*}$ under (29).

Concentrate now on the inspection of steady-state consumption levels. Computation yields the following outcome,

Proposition 4 In the optimal planners versus rule-of-thumb savers model, the following results apply: (i) if $s<\frac{\alpha \delta}{\rho+\delta}$, then $\left(c^{O}\right)^{*}>\left(c^{S}\right)^{*}$; (ii) if $s=\frac{\alpha \delta}{\rho+\delta}$, then $\left(c^{O}\right)^{*}=\left(c^{S}\right)^{*} ;$ (iii) if $s>\frac{\alpha \delta}{\rho+\delta}$, then $\left(c^{O}\right)^{*}<\left(c^{S}\right)^{*}$.

Proof See “Appendix”.

The savings rate of the non-optimizing agents is a fundamental determinant of the relation between balanced growth path consumption levels. A savings rate above 


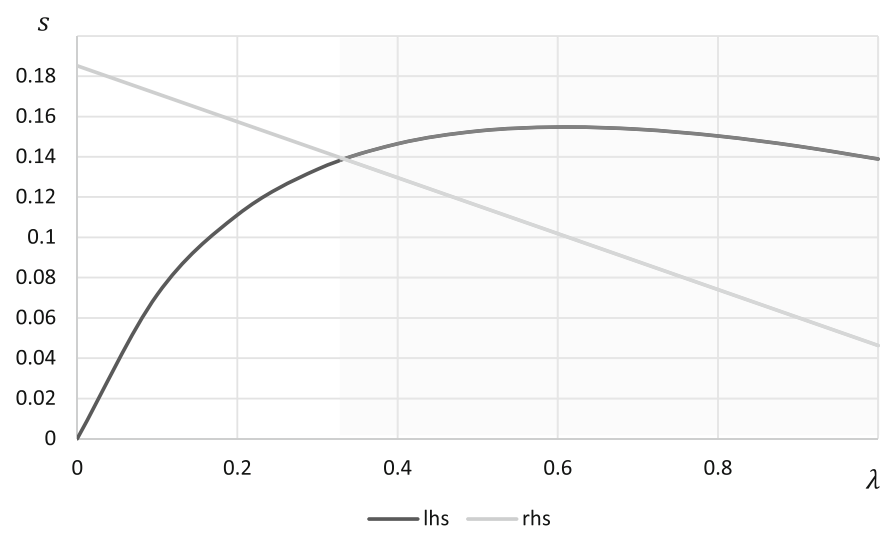

Fig. 6 Boundaries on $s$ in the optimal planners versus rule-of-thumb savers model

the threshold $s=\frac{\alpha \delta}{\rho+\delta}$ will imply that rule-of-thumb savers attain a steady-state level of consumption higher than the steady-state level of consumption of the optimal planners, while the opposite occurs under a savings rate below the threshold level. Because utility levels depend directly and exclusively on consumption, the derived results allow for a straightforward identification of whose agents attain higher utility levels in the balanced growth path.

In the current framework, assuming costs associated with optimal planning will have similar implications to the ones already explored in the case in which optimizers cohabited the economy with hand-to-mouth consumers. Namely, recovering parameter $\tau>0$, the steady-state value of per capita consumption of optimizers will be lowered to a value such that $\left.\left(c^{O}\right)^{*}\right|_{\tau}=\frac{1}{1+\tau}\left(c^{O}\right)^{*}$. Since $\left(c^{S}\right)^{*}$ does not suffer any change in the presence of the mentioned costs, equality $s=\frac{\alpha \delta}{\rho+\delta}$ now imposes $\left.\left(c^{O}\right)^{*}\right|_{\tau}<\left(c^{S}\right)^{*}$, or, from a different angle, to guarantee $\left.\left(c^{O}\right)^{*}\right|_{\tau}=\left(c^{S}\right)^{*}$, the constant savings rate of rule-of-thumb agents must be some value $s<\frac{\alpha \delta}{\rho+\delta}$.

Consider a brief illustrative numerical example (parameter values are the same as in Sect. 3). Figure 6 displays the boundaries on $s$ imposed by condition (30), against the share parameter $\widehat{\lambda}$; for the selected parameter values, the condition is verified as long as the darker line, which represents the lower bound of the condition, remains below the lighter line, which is the upper bound. In the specific case under appreciation, this requires $\widehat{\lambda}<1 / 3$, i.e., for rule-of-thumb savers to coexist in the specified economy with optimal planners, the number of non-optimizing agents cannot exceed one-third of the population.

Let $\widehat{\lambda}=1 / 9$, a value that satisfies (30), in this case imposing $0.07716<s<$ 0.16975. In Fig. 7, the consumption levels of rule-of-thumb savers and of optimizers are represented for the values of $s$ within the imposed interval. The two solid curves, which respect to $\left(c^{O}\right)^{*}$ and $\left(c^{S}\right)^{*}$, intersect at a specific savings rate, namely the threshold $s=\frac{\alpha \delta}{\rho+\delta}=0.13(8)$. To further confirm the results in Proposition 4, note 


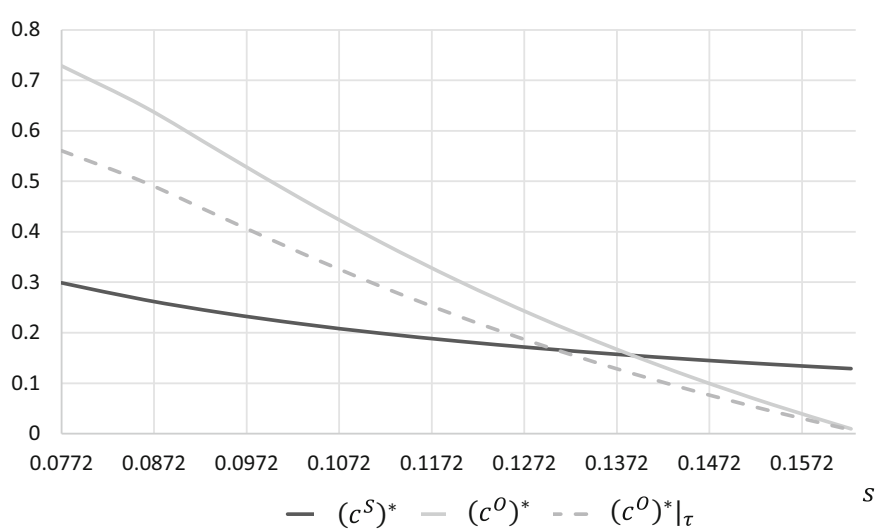

Fig. 7 Steady-state consumption levels in the optimal planners versus rule-of-thumb savers model

that if $s<0.13(8)$, then $\left(c^{O}\right)^{*}>\left(c^{S}\right)^{*}$, and if $s>0.13(8)$, then $\left(c^{O}\right)^{*}<\left(c^{S}\right)^{*}$. The dashed line represents $\left.\left(c^{O}\right)^{*}\right|_{\tau}$ for $\tau=0.3$; this last curve allows to illustrate the above discussed idea that costs of optimization reduce the steady-state value of the optimizers' consumption, with $\left.\left(c^{O}\right)^{*}\right|_{\tau}=\left(c^{S}\right)^{*}$ now locating at some value $s<0.13(8)$.

Finally, let us briefly address transitional dynamics in the scenario under examination; to simplify computation, the analysis is restricted to the specific case $s=\frac{\alpha \delta}{\rho+\delta}$. In the optimal planners versus rule-of-thumb savers model, if the savings rate is such that $s=\frac{\alpha \delta}{\rho+\delta}$, the corresponding equilibrium is saddle-path stable. In the three-dimensional model under consideration, one of the respective dimensions is unstable, and the other two are stable. To confirm this intuitive result, derive the linearized matricial system of the optimal planners versus rule-of-thumb savers intertemporal problem in the steadystate vicinity. One gets the following three-dimensional set of differential equations,

$$
\left[\begin{array}{c}
\dot{k^{S}}(t) \\
\dot{k^{O}}(t) \\
\dot{c^{O}}(t)
\end{array}\right]=\left[\begin{array}{ccc}
-(1-\alpha) \delta & 0 & 0 \\
0 & \rho+\delta & -1 \\
-j \widehat{\lambda}^{2} & -j(1-\widehat{\lambda})^{2} & 0
\end{array}\right]\left[\begin{array}{c}
k^{S}(t)-\left(k^{S}\right)^{*} \\
k^{O}(t)-\left(k^{O}\right)^{*} \\
c^{O}(t)-\left(c^{O}\right)^{*}
\end{array}\right]
$$

with $j=\frac{1}{\theta}(1-\alpha)(\rho+\delta)\left(\frac{1}{\alpha} \rho+\frac{1-\alpha}{\alpha} \delta\right)$. One of the eigenvalues of the Jacobian matrix in system (32) is $\varepsilon_{1}=-(1-\alpha) \delta<0$, which corresponds to a stable dimension; the other two eigenvalues are such that $\varepsilon_{2}+\varepsilon_{3}=\rho+\delta>0$ and $\varepsilon_{2} \varepsilon_{3}=-j(1-\widehat{\lambda})^{2}<0$. Thus, of the remaining two dimensions one is stable and the other is unstable (one of the eigenvalues is negative and the other positive), what has correspondence in the number of state variables and control variables, respectively.

\section{Discount rate heterogeneity and the hand-to-mouth threshold}

Evidence on intertemporal preference heterogeneity has been reported in various empirical studies (Samwick 1998; Gustman and Steinmeier 2005; Bozio et al. 2017). 
In general terms, these studies have identified an inverse relationship between the value of the discount rate and the share of individuals exhibiting the corresponding intertemporal preference. Based on such data, it is reasonable to assume that the distribution of discount rates across a population roughly approximates an exponential distribution. This is the assumption that is taken in the analysis in this section. Consider function $v[\rho(i)]$ below,

$$
v[\rho(i)]=\frac{1}{\widehat{\rho}} \exp \left[-\frac{1}{\widehat{\rho}} \rho(i)\right], \widehat{\rho}>0
$$

In expression (33), $\rho(i) \geq 0$ represents the discount rate of intertemporal consumption utility of an agent indexed by $i$, such that $\rho(i)=i, \forall i \geq 0$. Note that $\int_{0}^{\infty} v[\rho(i)] d i=1$, and, thus, $v[\rho(i)]$ is the share of agents at each discount rate $\rho(i)$. Consequently, $\int_{0}^{\infty} v[\rho(i)] \rho(i) d i=\widehat{\rho}$ translates the weighted average of the discount rates of everyone in the population.

The individual optimization problem in this economy consists in maximizing the intertemporal objective function

$$
V(t)=\int_{0}^{\infty} u[c(t, i)] \exp [-\rho(i) t] \mathrm{d} t
$$

where $c(t, i)$ is the consumption of agent $i$. The utility function is, as in previous analyses, a typical CRRA function. The resource constraint to which the maximization of (34) is subject to is similar to the already presented capital accumulation constraints,

$$
\dot{k}(t, i)=[r(t)-\delta] k(t, i)+w(t)-c(t, i), k(0)=k_{0} \text { given }
$$

Variable $k(t, i)$ is the stock of assets held by agent $i$ at date $t$. The rental rate of capital and the wage rate are, under competitive markets, identical to the ones presented in precedent sections. Therefore, constraint (35) is equivalent to:

$$
\dot{k}(t, i)=\left[(1-\alpha)+\alpha \frac{k(t, i)}{k(t)}\right] f[k(t)]-c(t, i)-\delta k(t, i)
$$

with $k(t)$ the aggregate per capita stock of capital, i.e., $k(t)=\int_{0}^{\infty} k(t, i) d i$. Solving the optimality problem, a typical equation of motion for consumption is derived,

$$
\dot{c}(t, i)=\frac{1}{\theta}\left\{\alpha\left[1+(1-\alpha)\left(1-\frac{k(t, i)}{k(t)}\right)\right] \frac{f[k(t)]}{k(t)}-[\rho(i)+\delta]\right\} c(t, i)
$$

The inspection of steady-state conditions leads to a relevant finding: in the heterogeneous discount rate setting, not all agents will follow the optimal plan.

In the heterogeneous discount rate model, there is a share of agents that would optimally select to hold a negative capital endowment in the steady-state. Because this violates the transversality condition, this group of agents will become hand-to-mouth 
consumers for whom $k^{*}(i)=0$. The percentage of consumers in such group is derived below.

From differential equation (37), it is straightforward to obtain

$$
k^{*}(i)=\frac{1}{1-\alpha}\left[(2-\alpha)-\frac{\rho(i)+\delta}{\alpha} \frac{k^{*}}{f\left(k^{*}\right)}\right] k^{*}
$$

Condition $k^{*}(i) \geq 0$ is a required transversality condition (agents cannot hold debt in the steady-state). Hence, the following constraint on the value of the individual's discount rate must be imposed,

$$
\rho(i) \leq(2-\alpha) \alpha \frac{f\left(k^{*}\right)}{k^{*}}-\delta
$$

Consequently, not all agents optimize; only those for whom the above constraint holds. In this circumstance, the share of agents that will accumulate capital is

$$
\int_{0}^{(2-\alpha) \alpha \frac{f\left(k^{*}\right)}{k^{*}}-\delta} v[\rho(i)] d i=1-\exp \left\{-\frac{1}{\widehat{\rho}}\left[(2-\alpha) \alpha \frac{f\left(k^{*}\right)}{k^{*}}-\delta\right]\right\}
$$

The remainder of the agents, a share $\bar{\lambda}=\exp \left\{-\frac{1}{\hat{\rho}}\left[(2-\alpha) \alpha \frac{f\left(k^{*}\right)}{k^{*}}-\delta\right]\right\}$, will then be hand-to-mouth consumers.

Figure 8 displays the distribution of agents for each discount rate level. To the left of the threshold (the dashed line), agents optimally choose to plan and, as a result, they will hold capital assets in the long-term and, therefore, perpetuate savings. Agents with a discount rate above the threshold (to the right of the dashed line) will cease to be optimizers and adopt a hand-to-mouth behavior; they will not save and will only consume, at every date, their wage income. Because agents cannot accumulate debt indefinitely, the transition to the hand-to-mouth state is the only solution they have; although they would prefer to maintain negative capital holdings in order to maximize consumption, the transversality condition prevents this to happen and, therefore, households remain in the knife-edge solution that is to remain a handto-mouth consumer.

In this setting, a strong degree of impatience leads agents to abandon optimal planning and to embrace a hand-to-mouth behavior; the threshold intertemporal discount rate is $\rho(i)=(2-\alpha) \alpha \frac{f\left(k^{*}\right)}{k^{*}}-\delta$.

Individual capital assets will correspond to a unique steady-state solution if the aggregate capital value $k^{*}$ exists and is unique. Observe that if all agents were optimizers, one would have

$$
\begin{aligned}
k^{*} & =\int_{0}^{\infty} k^{*}(i) \mathrm{d} i \\
& =\frac{1}{1-\alpha}\left[(2-\alpha)-\frac{\int_{0}^{\infty} v[\rho(i)] \rho(i) \mathrm{d} i+\delta}{\alpha} \frac{k^{*}}{f\left(k^{*}\right)}\right] k^{*}
\end{aligned}
$$




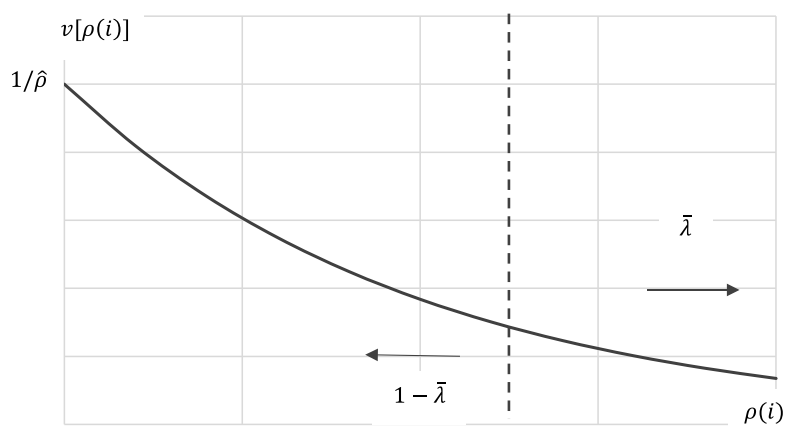

Fig. 8 Optimal planners and hand-to-mouth consumers in the heterogeneous discount rate model

$$
=\frac{1}{1-\alpha}\left[(2-\alpha)-\frac{\widehat{\rho}+\delta}{\alpha} \frac{k^{*}}{f\left(k^{*}\right)}\right] k^{*}
$$

what would imply the straightforward unique non-zero solution,

$$
\frac{f\left(k^{*}\right)}{k^{*}}=\frac{\widehat{\rho}+\delta}{\alpha}
$$

Because the agents that would optimally accumulate debt will, in fact, be hand-tomouth, the capital stock will be a lower value than the one that constitutes the solution for (41). Proceeding with the proper computation,

$$
\begin{aligned}
k^{*} & =\int_{0}^{(2-\alpha) \alpha \frac{f\left(k^{*}\right)}{k^{*}}-\delta} k^{*}(i) \mathrm{d} i \\
& =\frac{1}{1-\alpha}\left[(2-\alpha)-\frac{\int_{0}^{(2-\alpha) \alpha \frac{f\left(k^{*}\right)}{k^{*}}-\delta} v[\rho(i)] \rho(i) \mathrm{d} i+\delta}{\alpha} \frac{k^{*}}{f\left(k^{*}\right)}\right] k^{*} \\
& =\frac{1}{1-\alpha}\left[(2-\alpha)-\frac{\widehat{\rho}+\delta-\left[\widehat{\rho}+(2-\alpha) \alpha \frac{f\left(k^{*}\right)}{k^{*}}-\delta\right] \exp \left\{-\frac{1}{\hat{\rho}}\left[(2-\alpha) \alpha \frac{f\left(k^{*}\right)}{k^{*}}-\delta\right]\right\}}{\alpha} \frac{k^{*}}{f\left(k^{*}\right)}\right] k^{*}
\end{aligned}
$$

and, therefore,

$$
\frac{f\left(k^{*}\right)}{k^{*}}=\frac{\widehat{\rho}+\delta-\left[\widehat{\rho}+(2-\alpha) \alpha \frac{f\left(k^{*}\right)}{k^{*}}-\delta\right] \exp \left\{-\frac{1}{\hat{\rho}}\left[(2-\alpha) \alpha \frac{f\left(k^{*}\right)}{k^{*}}-\delta\right]\right\}}{(2-\alpha) \alpha}
$$

Equation (42) does not have an explicit solution, but it is straightforward to infer that $k^{*}$ exists and is unique. The l.h.s. of the equation is a decreasing function of $k^{*}$, given the decreasing marginal returns property; the r.h.s. is a U-shaped function that intersects the 1.h.s. just once. Figure 9 illustrates this relation, with the parameter values already assumed in previous examples.

For consumption, the outcome in Proposition 5 is derived, 


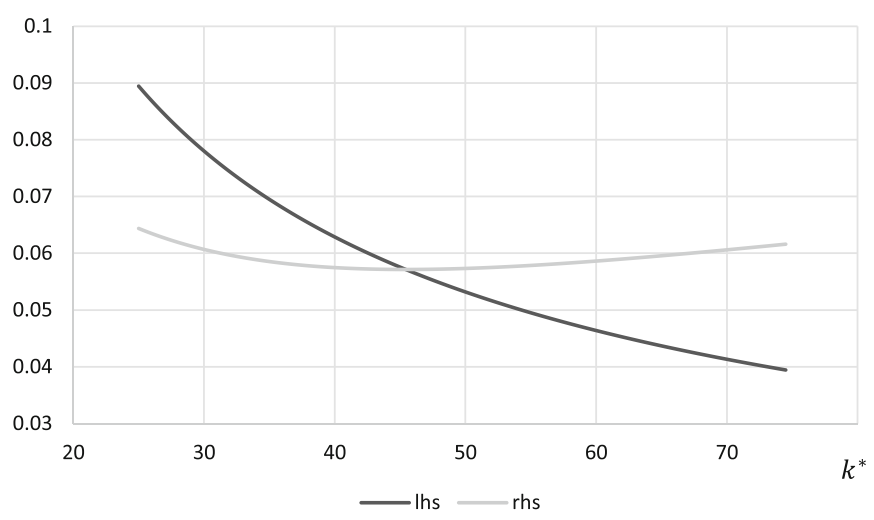

Fig. 9 Uniqueness of $k^{*}$ in the heterogeneous discount rates model

Proposition 5 In the heterogeneous discount rate model, optimal planners might accomplish a consumption level that is higher, equal or lower than the one of handto-mouth consumers. Specifically,

(i) If $\frac{f\left(k^{*}\right)}{k^{*}}=\frac{\delta}{\alpha}$, then $c^{*}(i)=\left(c^{H}\right)^{*}, \forall \rho(i)$;

(ii) If $\frac{f\left(k^{*}\right)}{k^{*}}>\frac{\delta}{\alpha}$, then $c^{*}(i)>\left(c^{H}\right)^{*}, \forall \rho(i)$; in this case, $c^{*}(i)$ declines as $\rho(i)$ increases;

(iii) If $\frac{f\left(k^{*}\right)}{k^{*}}<\frac{\delta}{\alpha}$, then $c^{*}(i)<\left(c^{H}\right)^{*}, \forall \rho(i)$; in this case, $c^{*}(i)$ increases as $\rho(i)$ increases;

In any case, $c^{*}(i)=\left(c^{H}\right)^{*}$ whenever $\rho(i)=(2-\alpha) \alpha \frac{f\left(k^{*}\right)}{k^{*}}-\delta$.

Proof See "Appendix".

Observe that the result in Proposition 5 derives essentially from the fact that we are comparing the steady-state rate of return on capital with the capital depreciation rate. When the rate of return on capital exceeds the depreciation rate, the optimal planners attain higher consumption levels than hand-to-mouth consumers. If the opposite occurs, net returns from capital are negative and those agents earning solely wage income (the hand-to-mouth) will benefit from higher total factor income and, thus, will be able to access higher consumption levels.

In Fig. 10, steady-state consumption levels for different discount rates are drawn, under each of the three possible scenarios. Differently from what one has observed to occur in the optimal planners versus hand-to-mouth consumers model with discount rate homogeneity, discount rate heterogeneity does not deliver a straightforward steady-state consumption outcome. Depending on parameter values, the steady-state level of consumption of a hand-to-mouth agent can be equal, lower or higher than the steady-state consumption of an optimizer. Therefore, hand-to-mouth agents may experience a higher steady-state utility than optimizers, namely if the average product of capital is lower than the ratio between the capital depreciation rate and the output-capital elasticity.

Three panels are sketched, for each one of the possibilities that were uncovered for ratio $\frac{f\left(k^{*}\right)}{k^{*}}$. 

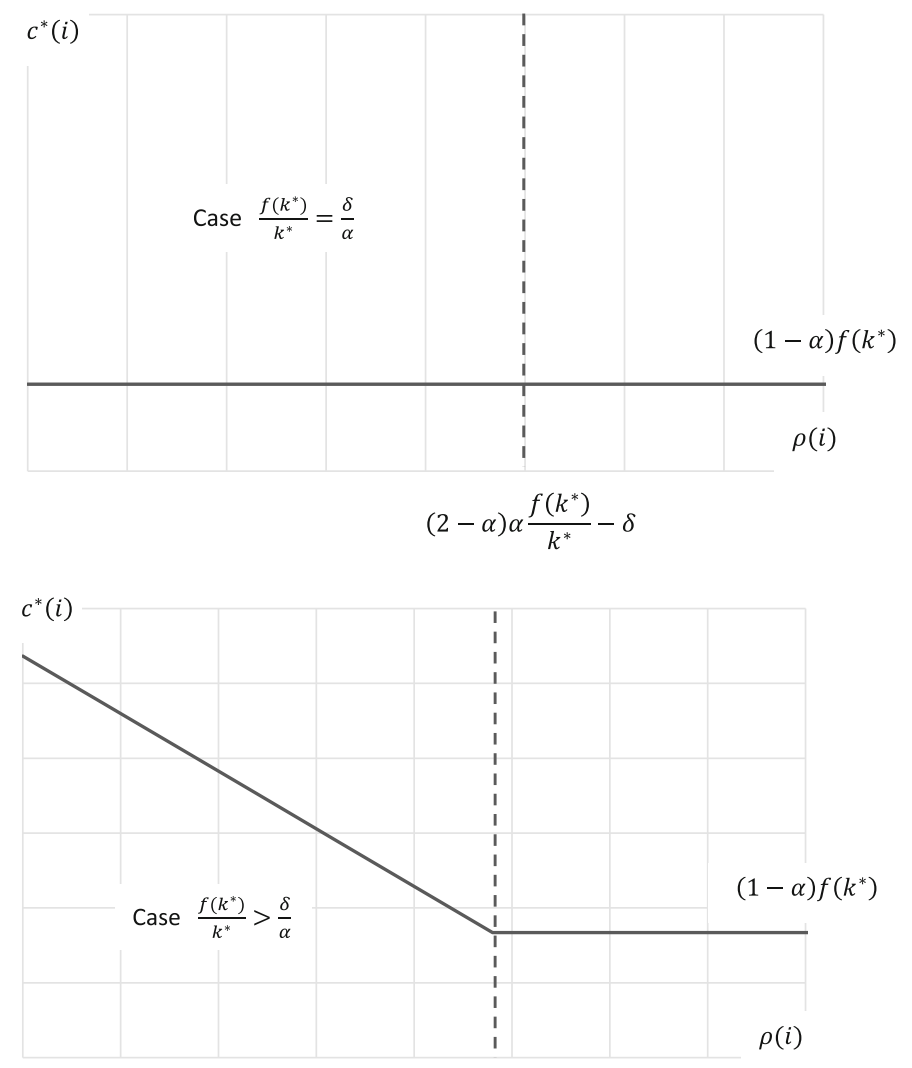

$$
(2-\alpha) \alpha \frac{f\left(k^{*}\right)}{k^{*}}-\delta
$$

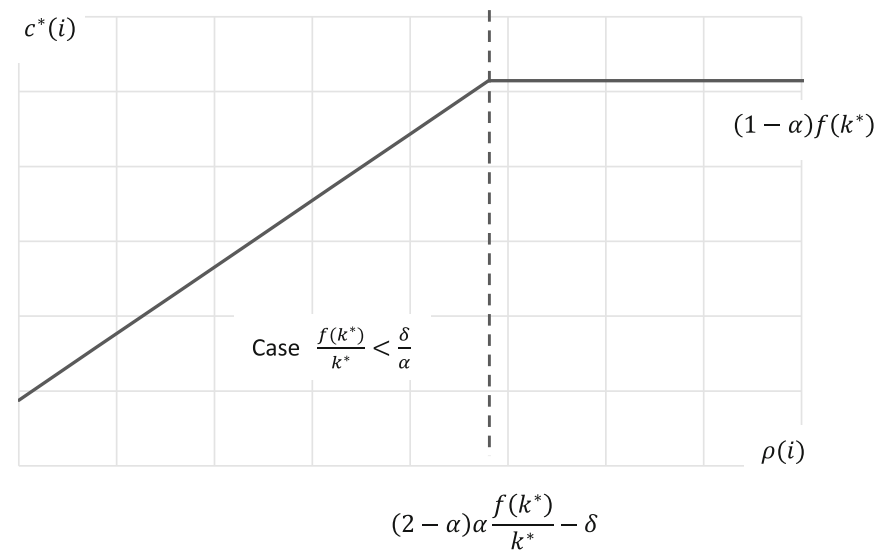

Fig. 10 Steady-state consumption in the heterogeneous discount rate model 
Transitional dynamics regarding the motion of the variables underlying the behavior of optimal planners will not yield results qualitatively different from those already obtained (saddle-path stability), since the relevant differential equations generate the same type of dynamics one has already characterized in precedent sections. A multidimensional system of differential equations must be considered in this case, though, because the dynamics of each single $k(t, i)$ variable is interconnected with all the other capital variables.

\section{Widespread rule-of-thumb behavior}

In this section, optimal planners are suppressed from the analysis and all agents are assumed to be hand-to-mouth consumers or rule-of thumb savers. The heuristic to adopt is an adapted version of Deaton's (1992) consumption rule, a rule for consumption decisions that this author considered to be a good replacement for optimal intertemporal choice when assessing the empirical evidence on consumption-savings choices.

The consumption function hereafter under consideration will be a static function where consumption is driven by the confrontation between desired consumption and disposable income,

$$
c(t, i)= \begin{cases}k(t, i), & \text { if } y(t, i) \leq c^{D}(t, i) \wedge k(t, i) \leq c^{D}(t, i) \\ c^{D}(t, i), & \text { if } y(t, i) \leq c^{D}(t, i) \wedge k(t, i)>c^{D}(t, i) \\ c^{D}(t, i)+\zeta\left[y(t, i)-c^{D}(t, i)\right], & \text { if } y(t, i)>c^{D}(t, i)\end{cases}
$$

In Eq. (43), $c^{D}(t, i)$ stands for the level of consumption desired by agent $i$. Agents are heterogeneous: some desire to consume less than the income they receive, while others adopt the antagonist behavior. Reasons for this disparity on savings behavior can be traced back to empirical evidence, namely the evidence already discussed in Sect. 2 following the research undertaken by Gerhard et al. (2018): people adopt different attitudes toward savings given their distinct psychological profiles (including personality traits) and financial literacy competencies.

Households who set a desired consumption level below current income will save, according to Eq. (43), a share $\zeta \in(0,1)$ of their excess income (income less desired consumption); households who desire to consume more than their income might be separated into two groups: those who desire a level of consumption lower than their level of wealth and those who want to consume their current wealth or more; these last ones consume their entire stock of assets, $k(t, i)$. The mentioned behaviors correspond, respectively, to the third, the second, and the first conditions in consumption function (43). As it will be remarked, in the steady-state the first two profiles in Eq. (43) merge into a single profile.

Let $c^{D}(t, i)$ be a proportion of $y(t, i)$, such that $c^{D}(t, i)=[1+\sigma(i)] y(t, i)$. If $\sigma(i)<0$, the third case of (43) holds; otherwise, one of the first two circumstances 
applies. Equation (43) is rewritten under the form

$$
c(t, i)= \begin{cases}k(t, i), & \text { if } \sigma(i) \geq \frac{k(t, i)}{y(t, i)}-1 \\ {[1+\sigma(i)] y(t, i),} & \text { if } 0 \leq \sigma(i)<\frac{k(t, i)}{y(t, i)}-1 \\ {[1+(1-\zeta) \sigma(i)] y(t, i),} & \text { if } \sigma(i)<0\end{cases}
$$

The income of an agent is given by the, by now, familiar expression

$$
y(t, i)=r(t) k(t, i)+w(t)=\left[(1-\alpha)+\alpha \frac{k(t, i)}{k(t)}\right] f[k(t)]
$$

with $k(t)$ the average per capita capital holdings. The capital accumulation constraint of each type of agent is, with consumption set by Eq. (44),

$$
\dot{k}(t, i)= \begin{cases}y(t, i)-(1+\delta) k(t, i), & \text { if } \sigma(i) \geq \frac{k(t, i)}{y(t, i)}-1 \\ -\sigma(i) y(t, i)-\delta k(t, i), & \text { if } 0 \leq \sigma(i)<\frac{k(t, i)}{y(t, i)}-1, k(0, i)=k_{0, i} \text { given } \\ -(1-\zeta) \sigma(i) y(t, i)-\delta k(t, i), & \text { if } \sigma(i)<0\end{cases}
$$

The first result of the non-optimization framework concerns the initial locus, at $t=$ 0 . Take the non-optimization scenario and consider that every agent $i$ in the economy is endowed with an identical wealth, i.e., $k(0, i)=k_{0}, \forall i$. Under this distribution of wealth, given consumption function (44), the following is a true condition,

$$
\left.k_{0}\right|_{\sigma(i) \geq \frac{k_{0}}{f\left(k_{0}\right)}-1}>\left.[1+\sigma(i)] f\left(k_{0}\right)\right|_{0 \leq \sigma(i)<\frac{k_{0}}{f\left(k_{0}\right)}-1}>\left.[1+(1-\zeta) \sigma(i)] f\left(k_{0}\right)\right|_{\sigma(i)<0}
$$

Observe that if $\sigma(i)<\frac{k_{0}}{f\left(k_{0}\right)}-1$ then $[1+\sigma(i)] f\left(k_{0}\right)<k_{0}$, and that if $\sigma(i)<0$ then $[1+(1-\zeta) \sigma(i)] f\left(k_{0}\right)<f\left(k_{0}\right)$. These conditions guarantee the veracity of the above double inequality. The double inequality highlights a tautological result: individual agents who spend a larger portion of their wealth endowment in the shortrun and, thus, do not save, are necessarily the ones accessing larger consumption levels at the initial date. This result is relevant as a starting point to address transitional dynamics and long-term steady-state outcomes.

Next, concentrate the attention on the other extreme of the time line, i.e., on the steady-state. The relevant outcome is systematized in Proposition 6.

Proposition 6 In the consumption heuristic model, two types of agents will populate the economy in the steady-state: hand-to-mouth consumers $[\sigma(i)>0]$ and rule-ofthumb savers $[\sigma(i)<0]$. In the first group, all agents consume a same amount of resources; in the second group, the consumption level is contingent on the savings' preferences of the agents and amounts to

$$
c^{*}(i)=-\frac{1+(1-\zeta) \sigma(i)}{(1-\zeta) \sigma(i)} \delta k^{*}(i)
$$


Proof See "Appendix".

In the steady-state, two additional results are worthwhile highlighting. First, observe that the lower is the value of the desired consumption of the agents who save, the lower will also be the value of the steady-state consumption-capital ratio. This result holds because Eq. (47) is equivalent to $\frac{c^{*}(i)}{k^{*}(i)}=-\left[1+\frac{1}{(1-\zeta) \sigma(i)}\right] \delta$, and such expression makes it clear that the larger is $\sigma(i)$ in absolute value (corresponding to a lower desired consumption - income ratio), the lower will also be the value of the ratio $\frac{c^{*}(i)}{k^{*}(i)}$. The second result compares the steady-state consumption of savers and non-savers, namely note that if the following condition holds,

$$
\frac{k^{*}(i)}{k^{*}}<-\frac{1-\alpha}{\alpha} \frac{(1-\zeta) \sigma(i)}{1+(1-\zeta) \sigma(i)}
$$

then an agent $i$ that saves will access a higher steady-state consumption level than a hand-to-mouth agent. To confirm this result take inequality $c^{*}(i)>\left(c^{H}\right)^{*}$ and the already presented expressions for each of the consumption steady-state values; the above condition follows after rearranging.

Steady-state results formalized above do not offer unequivocal guidance on who will benefit the most, in what respects steady-state consumption (and, thus, steady-state utility). This is because such results are sensitive to the distribution of agents across desired consumption levels. Specific intuitive results are straightforward to obtain once a simplifying assumption is taken, namely the assumption that the agents that save share a same desired consumption - income ratio, i.e., if one defines parameter $\bar{\sigma}=-\sigma(i), \forall \sigma(i)<0$. In this case, the consumption level of a saver will be $\left(c^{S}\right)^{*}=$ $\frac{1+(1-\zeta) \bar{\sigma}}{(1-\zeta) \bar{\sigma}} \delta k^{*}$; condition (53) simplifies to $(1-\zeta) \bar{\sigma} f\left(k^{*}\right)=\delta k^{*}$, and, thus, $\left(c^{S}\right)^{*}>$ $\left(c^{H}\right)^{*}$ now directly corresponds to a true condition. The balanced growth utility of savers will overcome the utility of hand-to-mouth agents (if one assumes that both types of agents share a same utility function, and this has, as single argument, consumption).

In this setting, one finds a rationale for agents to choose to be savers or, instead, hand-to-mouth. Hand-to-mouth consumers are the agents with a high degree of impatience toward consumption, thus implicitly selecting a strong discount rate of future utility. Savers are the agents who are willing to renounce to immediate consumption to guarantee higher long-term consumption levels, hence implicitly taking a relatively low discount rate.

In Fig. 11, a straightforward example of the framework under appreciation is presented. Three agents are considered; these agents share a same initial endowment of capital, $k(0)=1$, and are such that $\sigma(I)=0.4, \sigma(I I)=0.1, \sigma(I I I)=-0.25$; one also takes $\zeta=0.3$, and the other parameter values are the same as in previous analyses. The figure points in the direction of the expected outcome: agents who desire to consume more than their current income converge to a same steady-state; this steady-state corresponds to a consumption level that, in the long-run, is lower than the consumption of the agent with a positive savings rate.

This last framework adds new knowledge relatively to prior analyses because, in the current context, it is possible to explicitly present transitional dynamics together 


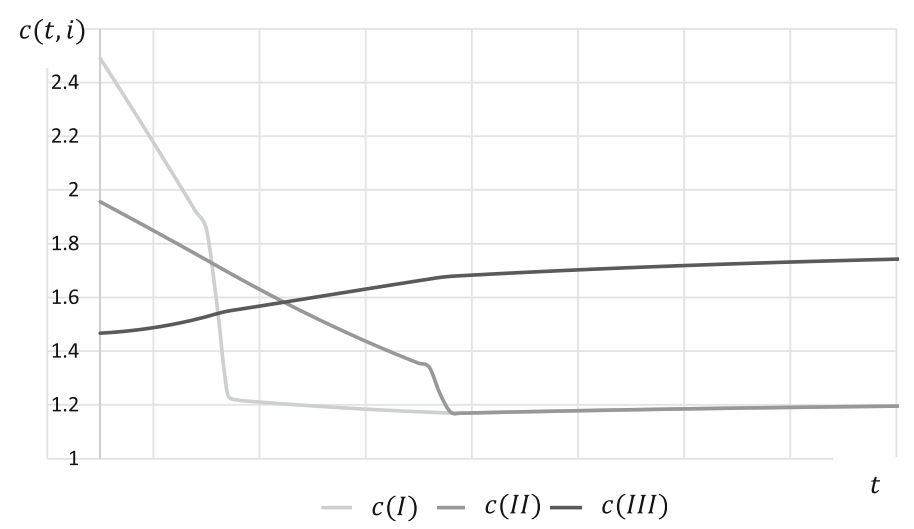

Fig. 11 Transitional dynamics in the hand-to-mouth versus rule-of-thumb agents model

with long-term outcomes, what allows for an integrated analysis of the short-term / long-term conflict regarding individual preferences.

\section{Conclusion}

The Ramsey growth model is a simple but powerful conceptual device that allows to understand the consumption - savings trade-off in an integrated intertemporal perspective. The typical formal presentation of the model takes a representative agent. Underlying this framework is the implausible assumption that all individuals make the same choices and, more specifically, that they discount the future at the same rate. Expanding such framework to contemplate heterogeneity of behavior and the coexistence of optimal planners, rule-of-thumb savers and hand-to-mouth consumers, it was possible to unveil novel steady-state results and transitional dynamics. The introduction of different kinds of heuristics and optimization costs associated with planning behavior led to a more general framework, where it is not straightforward to conclude that pursuing optimal plans is the best solution at all times and for all agents.

In synthesis, the most relevant findings associated with the four developed models are as follows:

(i) In the optimizers versus poor hand-to-mouth framework, the steady-state consumption of the optimal planners exceeds the consumption of the non-optimizers; the introduction of optimization costs may revert this result, as long as the share of hand-to-mouth consumers remains relatively low;

(ii) In the optimizers versus wealthy hand-to-mouth framework, the steady-state consumption levels of the two groups of agents are identical; the presence of optimization costs attributes, at this respect, supremacy to the wealthy hand-tomouth agents;

(iii) In the optimizers versus rule-of-thumb savers setting, coexistence of the two types of agents requires the constant savings rate of the second group of agents 
to obey to a specific boundary condition; if this condition is satisfied, the relation between steady-state consumption values will depend on the savings rate of the non-optimizers: the larger this is, the lower will be the consumption of optimal planners relatively to the consumption of rule-of-thumb savers;

(iv) In the discount rate, heterogeneity setting, a share of hand-to-mouth consumers emerges endogenously, and the relation between steady-state consumption levels of the two groups will be contingent on parameter values;

(v) In the rule-of-thumb savers versus hand-to-mouth consumers model, long-term consumption levels will depend on the number of agents and on the distribution of desired consumption across agents; under reasonable circumstances, the steadystate consumption of hand-to-mouth consumers remains below the steady-state consumption of the agents who manage to save a percentage of their disposable income.

Acknowledgements Financial support from CEFAGE research center, under FCT (Portuguese Foundation for Science and Technology) strategic program UID/ECO/04007/2019, and from MacroViews project (Lisbon Polytechnic Institute), is gratefully acknowledged. I also express my gratitude to two anonymous referees for their valuable input and their detailed and insightful comments and suggestions, which helped in improving the paper's contents. The usual disclaimer applies.

\section{Appendix: Proofs of Propositions}

Proof of Proposition 1 The steady-state consumption of an optimal planner is displayed in Eq. (10); the consumption of a hand-to-mouth decision-maker is $\left(c^{H}\right)^{*}=(1-$ a) $f\left[(1-\lambda)\left(k^{O}\right)^{*}\right]$. Condition $\left(c^{O}\right)^{*}>\left(c^{H}\right)^{*}$ is equivalent to $\left(\frac{1}{\alpha} \rho+\frac{1-\alpha}{\alpha} \delta\right)\left(k^{O}\right)^{*}>$ $(1-\alpha) f\left[(1-\lambda)\left(k^{O}\right)^{*}\right]$. Replacing, in this inequality, ratio $\alpha \frac{f\left[(1-\lambda)\left(k^{O}\right)^{*}\right]}{\left(k^{O}\right)^{*}}$ by the equivalent expression in Eq. (9), it is straightforward to simplify the inequality to $\rho+(1-\alpha) \lambda \delta>0$. This is a true condition, implying that, independently of the value of parameter $\lambda$, consumption of a planner is always a higher value, in the steady-state, than the consumption of a hand-to-mouth agent.

Proof of Proposition 2 Solve $\left(c^{O}\right)^{*}>\left(c^{H}\right)^{*}$, with the value of $\left(c^{O}\right)^{*}$ given by (14) and the value of $\left(c^{H}\right)^{*}$ equal to the marginal productivity of labor, i.e., $\frac{1}{1+\tau}\left(\frac{1}{\alpha} \rho+\frac{1-\alpha}{\alpha} \delta\right)\left(k^{O}\right)^{*}>(1-\alpha) f\left[(1-\lambda)\left(k^{O}\right)^{*}\right]$. Resorting to Eq. (9) to simplify the inequality and rearranging the corresponding expression, one obtains condition (15).

Proof of Proposition 4 Taking into consideration expressions (29) and (31), variable $c^{S}(t)$ is, in the steady-state, equivalent to:

$$
\left(c^{S}\right)^{*}=\frac{1-s}{s} \delta k^{*}
$$


The steady-state consumption of an optimal planner is calculated from $\dot{k^{O}}(t)=0$, given the already computed steady-state relations,

$$
\left(c^{O}\right)^{*}=\left[\frac{\left(1+\frac{\alpha}{1-\hat{\lambda}} \Psi\right)\left(1-\frac{1}{\lambda} \Psi\right)}{s\left(1-\frac{\alpha}{\lambda} \Psi\right)}-\left(1+\frac{1}{1-\widehat{\lambda}} \Psi\right)\right] \delta k^{*}
$$

If $s=\frac{\alpha \delta}{\rho+\delta}$ and, hence, $\Psi=0$, it is straightforward to arrive to outcome $\left(c^{S}\right)^{*}=\left(c^{O}\right)^{*}=\left(\frac{1}{\alpha} \rho+\frac{1-\alpha}{\alpha} \delta\right) k^{*}$. In the scenario where $s<\frac{\alpha \delta}{\rho+\delta}$, one knows that $-(1-\widehat{\lambda})<\Psi<0$. Replacing any value of $\Psi$ within this interval into expression ( 50), one obtains a value of $\left(c^{O}\right)^{*}$ larger than $\frac{1-s}{s} \delta k^{*}$, i.e., larger than $\left(c^{S}\right)^{*}$. The opposite occurs for $s>\frac{\alpha \delta}{\rho+\delta}$; in this case $0<\Psi<\widehat{\lambda}$, and, for any $\Psi$ such that $\left(c^{O}\right)^{*}>0,\left(c^{O}\right)^{*}$ is maintained in a value that is lower than $\frac{1-s}{s} \delta k^{*}$.

Proof of Proposition 5 Hand-to-mouth consumers will consume their wage income, i.e.,

$$
\left(c^{H}\right)^{*}=(1-\alpha) f\left(k^{*}\right)
$$

while the steady-state consumption level of an optimizer is calculated by applying condition $\dot{k}(t, i)=0$ to constraint (36),

$$
c^{*}(i)=\frac{1}{1-\alpha}\left[\frac{f\left(k^{*}\right)}{k^{*}}+\frac{\rho(i)+\delta}{\alpha} \delta \frac{k^{*}}{f\left(k^{*}\right)}-\rho(i)-(3-\alpha) \delta\right] k^{*}
$$

Whether $c^{*}(i)$ increases or falls with a change in $\rho(i)$ depends on the sign of the following partial derivative of (52): $\frac{\partial c^{*}(i)}{\partial \rho(i)}=\frac{1}{1-\alpha}\left[\frac{\delta}{\alpha} \frac{k^{*}}{f\left(k^{*}\right)}-1\right] k^{*}$. If $\frac{f\left(k^{*}\right)}{k^{*}}>\frac{\delta}{\alpha}$, then $\frac{\partial c^{*}(i)}{\partial \rho(i)}<0$ and $c^{*}(i)$ decreases as the discount rate $\rho(i)$ increases; the opposite occurs for $\frac{f\left(k^{*}\right)}{k^{*}}<\frac{\delta}{\alpha}$. In the boundary case $\frac{f\left(k^{*}\right)}{k^{*}}=\frac{\delta}{\alpha}, c^{*}(i)=\frac{1-\alpha}{\alpha} \delta k^{*}$ for all feasible values of $\rho(i)$. Note, as well, that if $\frac{f\left(k^{*}\right)}{k^{*}}=\frac{\delta}{\alpha}$, then, according to (51), also $\left(c^{H}\right)^{*}=\frac{1-\alpha}{\alpha} \delta k^{*}$.

Regardless of the upward or downward movement of $c^{*}(i)$ as the discount rate increases, the threshold point that marks the transition from planning to hand-to-mouth behavior, which takes place at the value of $\rho(i)$ that satisfies condition $\frac{f\left(k^{*}\right)}{k^{*}}=\frac{\rho(i)+\delta}{(2-\alpha) \alpha}$, is always such that $c^{*}(i)=\left(c^{H}\right)^{*}$. Hence, three outcomes are possible, depending on the value of ratio $\frac{f\left(k^{*}\right)}{k^{*}}$. If $\frac{f\left(k^{*}\right)}{k^{*}}=\frac{\delta}{\alpha}$, then $c^{*}(i)=\left(c^{H}\right)^{*}=\frac{1-\alpha}{\alpha} \delta k^{*}, \forall \rho(i) \geq 0$; if $\frac{f\left(k^{*}\right)}{k^{*}}>\frac{\delta}{\alpha}$, then $c^{*}(i)$ starts at a value such that $c^{*}(i)>\left(c^{H}\right)^{*}$ for $\rho(i)=0$ and it declines until it reaches $c^{*}(i)=\left(c^{H}\right)^{*}$ at point $\frac{f\left(k^{*}\right)}{k^{*}}=\frac{\rho(i)+\delta}{(2-\alpha) \alpha}$; if $\frac{f\left(k^{*}\right)}{k^{*}}<\frac{\delta}{\alpha}$, then $c^{*}(i)$ starts at a value such that $c^{*}(i)<\left(c^{H}\right)^{*}$ for $\rho(i)=0$ and it increases until it reaches $c^{*}(i)=\left(c^{H}\right)^{*}$ at point $\frac{f\left(k^{*}\right)}{k^{*}}=\frac{\rho(i)+\delta}{(2-\alpha) \alpha}$.

Proof of Proposition 6 The first two conditions of dynamic equation (46) imply that $k(t, i)$ converges to zero over time: agents will not accumulate capital in the long-term 
and their consumption level is $\left(c^{H}\right)^{*}=w^{*}=(1-\alpha) f\left(k^{*}\right)$, i.e., these agents are hand-to-mouth consumers. The remaining agents are rule-of-thumb savers for which we derive the following steady-state outcome,

$$
-(1-\zeta) \sigma(i)\left[(1-\alpha)+\alpha \frac{k^{*}(i)}{k^{*}}\right] f\left(k^{*}\right)=\delta k^{*}(i)
$$

From consumption function (44), it is straightforward to compute the equality in the proposition, once one takes into account relation (53).

\section{References}

Acemoglu D, Cao D (2015) Innovation by entrants and incumbents. J Econ Theory 157:255-294

Acharya S, Dogra K (2020) Understanding HANK: insights from a PRANK. Econometrica 88:1113-1158

Aghion P, Akcigit U, Howitt P (2015) Lessons from schumpeterian growth theory. Am Econ Rev 105:94-99

Akcigit U, Celik MA, Greenwood J (2016) Buy, keep, or sell: economic growth and the market for ideas. Econometrica 84:943-984

Allen TW, Carroll CD (2001) Individual learning about consumption. Macroecon Dyn 5:255-271

Amato JD, Laubach T (2003) Rule-of-thumb behaviour and monetary policy. Eur Econ Rev 47:791-831

Ballot G, Mandel A, Vignes A (2015) Agent-based modelling and economic theory: where do we stand? J Econ Interac Coord 10:199-220

Benartzi S, Thaler R (2007) Heuristics and biases in retirement savings behavior. J Econ Perspect 21:81-104 Benhabib J, Perla J, Tonetti C (2014) Catch-up and fall-back through innovation and imitation. J Econ Growth 19:1-35

Bilbiie FO (2017) The new keynesian cross: understanding monetary policy with hand-to-mouth households. CEPR Discussion Papers 11989, C.E.P.R. Discussion Papers

Bozio A, Laroque G, O’Dea C (2017) Discount rate heterogeneity among older households: a puzzle? J Popul Econ 30:647-680

Browning M, Lusardi A (1996) Household saving: micro theories and micro facts. J Econ Lit 34:1797-1855

Buera FJ, Lucas RE (2018) Idea flows and economic growth. Ann Rev Econ 10:315-345

Campbell JY, Mankiw NG (1990) Permanent income, current income, and consumption. J Bus Econ Stat 8:265-279

Cass D (1965) Optimum growth in an aggregative model of capital accumulation. Rev Econ Stud 32:233240

Cho D, Kim KH (2013) Deep habits, rule-of-thumb consumers, and fiscal policy. Korean Econ Rev 29:305327

Clarida R, Gali G, Gertler M (1999) The science of monetary policy: a new Keynesian perspective. J Econ Lit 37:1661-1707

Colciago A (2011) Rule-of-thumb consumers meet sticky wages. J Money Credit Bank 43:325-353

Dawid H, Harting P, Hoog S, Neugart M (2019) Macroeconomics with heterogeneous agent models: fostering transparency, reproducibility and replication. J Evol Econ 29:467-538

De Grauwe P (2010) Top-down versus bottom-up macroeconomics. CESifo Econ Stud 56:465-497

Deaton A (1992) Household Saving in LDCs: Credit Markets, Insurance and Welfare. Scandinavian Journal of Economics 94:253-273

DellaVigna S (2009) Psychology and economics: evidence from the field. J Econ Lit 47:315-372

Di Bartolomeo G, Rossi L, Tancioni M (2011) Monetary policy, rule-of-thumb consumers and external habits: a G7 comparison. Appl Econ 43:2721-2738

Doepke M, Tertilt M (2016) Families in macroeconomics. NBER working paper $\mathrm{n}^{\circ} 22068$

Dosi G, Roventini A (2019) More is different... and complex! the case for agent-based macroeconomics. J Evol Econ 29:1-37

Dosi G, Napoletano M, Roventini A, Stiglitz JE, Treibich T (2017) Rational heuristics? Expectations and behaviors in evolving economies with heterogeneous interacting agents. LEM papers series 2017/31, Sant'Anna School of Advanced Studies, Pisa, Italy

Gabaix X (2014) A sparsity-based model of bounded rationality. Quart J Econ 129:1661-1710 
Gali J, López-Salido JD, Vallés J (2004) Rule-of-thumb consumers and the design of interest rate rules. J Money Credit Bank 36:739-763

Gali J, López-Salido JD, Vallés J (2007) Understanding the effects of government spending on consumption. J Eur Econ Assoc 5:227-270

Gerhard P, Gladstone JJ, Hoffmann AOI (2018) Psychological characteristics and household savings behavior: the importance of accounting for latent heterogeneity. J Econ Behav Organ 148:66-82

Gigerenzer G, Brighton H (2009) Homo heuristicus: why biased minds make better inferences. Top Cogn Sci 1:107-143

Gigerenzer G, Gaissmaier W (2011) Heuristic decision making. Annu Rev Psychol 62:451-482

Goodfriend M, King RG (1997) The new neoclassical synthesis and the role of monetary policy. In: Bernanke BS, Rotemberg JJ (eds) NBER macroeconomics annual, vol 12. MIT Press, Cambridge, pp 231-296

Grossman GM, Helpman E (2015) Globalization and growth. Am Econ Rev 105:100-104

Gualdi S, Tarzia M, Zamponi F, Bouchaud JP (2017) Monetary policy and dark corners in a stylized agent-based model. J Econ Interact Coord 12:507-537

Guerini M, Napoletano M, Roventini A (2018) No man is an island: the impact of heterogeneity and local interactions on macroeconomic dynamics. Econ Model 68:82-95

Gustman AL, Steinmeier TL (2005) The social security early entitlement age in a structural model of retirement and wealth. J Public Econ 89:441-463

Haldane AG, Turrell AE (2018) An interdisciplinary model for macroeconomics. Oxford Rev Econ Policy 34:219-251

Haldane AG, Turrell AE (2019) Drawing on different disciplines: macroeconomic agent-based models. J Evol Econ 29:39-66

Havranek T, Sokolova A (2020) Do consumers really follow a rule of thumb? Three thousand estimates from 144 studies say probably not. Rev Econ Dyn 35:97-122

Kaplan G, Violante GL, Weidner J (2014) The wealthy hand-to-mouth. Brookings Papers on Economic Activity, ${ }^{\circ} 1$, pp $77-138$

Kaplan G, Moll B, Violante GL (2018) Monetary policy according to HANK. Am Econ Rev 108:697-743

Kiley MT (2010) Habit persistence, nonseparability between consumption and leisure, or rule-of-thumb consumers: which accounts for the predictability of consumption growth? Rev Econ Stat 92:679-683

Koopmans TC (1965) On the concept of optimal economic growth. In: The econometric approach to development planning. Amsterdam: North Holland

Krusell P, Smith AA Jr (1996) Rules of thumb in macroeconomic equilibrium. A quantitative analysis. J Econ Dyn Control 20:527-558

Kydland FE, Prescott EC (1982) Time to build and aggregate fluctuations. Econometrica 50:1345-1370

Lettau M, Uhlig H (1999) Rules of thumb versus dynamic programming. Am Econ Rev 89:148-174

Love DA (2013) Optimal rules of thumb for consumption and portfolio choice. Econ J 123:932-961

Lucas RE, Moll B (2014) Knowledge growth and the allocation of time. J Polit Econ 122:1-51

Lusardi A (1996) Permanent income, current income, and consumption: evidence from two panel data sets. J Bus Econ Stat 14:81-90

Lusardi A (2002) Explaining why so many households do not save. Darthmouth College working paper

Natvik GJ (2012) Government spending shocks and rule-of-thumb consumers with steady-state inequality. Scand J Econ 114:1414-1436

Ramsey F (1928) A mathematical theory of saving. Econ J 38:543-559

Reis R (2006) Inattentive consumers. J Monet Econ 53:1761-1800

Rossi R (2014) Designing monetary and fiscal policy rules in a new keynesian model with rule-of-thumb consumers. Macroecon Dyna 18:395-417

Samwick AA (1998) Discount rate heterogeneity and social security reform. J Dev Econ 57:117-146

Stokey NL (2015) Catching up and falling behind. J Econ Growth 20:1-36

Weber CE (2002) Intertemporal non-separability and rule of thumb consumption. J Monet Econ 49:293-308

Winter JK, Schlafmann K, Rodepeter R (2012) Rules of thumb in life-cycle saving decisions. Econ J 122:479-501

Woodford M (2003) Interest and prices: foundations of a theory of monetary policy. Princeton University Press, Princeton, NJ

Publisher's Note Springer Nature remains neutral with regard to jurisdictional claims in published maps and institutional affiliations. 